\title{
Center For Advanced Energy Studies (CAES) Program Plan
}

September 2005

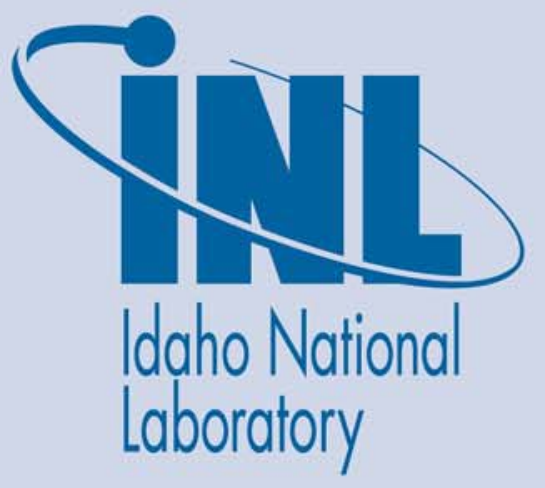

The INL is a U.S. Department of Energy National Laboratory operated by Battelle Energy Alliance 

INL/EXT-05-00729

\section{Center for Advanced Energy Studies (CAES) Program Plan}

September 2005

Idaho National Laboratory

Idaho Falls, Idaho 83415

Prepared for the

U.S. Department of Energy

Under DOE Idaho Operations Office

Contract DE-AC07-05ID14517 



\section{EXECUTIVE SUMMARY}

The world is facing critical energy-related challenges regarding world and national energy demands, advanced science and energy technology delivery, nuclear engineering educational shortfalls, and adequately trained technical staff. Resolution of these issues is important for the United States to ensure a secure and affordable energy supply, which is essential for maintaining U.S. national security, continued economic prosperity, and future sustainable development.

One way that the U.S. Department of Energy (DOE) is addressing these challenges is by tasking the Battelle Energy Alliance, LLC (BEA) with developing the Center for Advanced Energy Studies (CAES) at the Idaho National Laboratory (INL). By 2015, CAES will be a self-sustaining, world-class, academic and research institution where the INL; DOE; Idaho, regional, and other national universities; and the international community will cooperate to conduct critical energy-related research, classroom instruction, technical training, policy conceptualization, public dialogue, and other events.

The Center for Advanced Energy Studies will be central to the nuclear renaissance and an integrating element of the INL transformation, including workforce reinvigoration and diversification, strategic hires, and culture change. By growing research partnerships via a university network, CAES will enable university and other organizational access to INL facilities. Although ultimately evolving into an independent, nonprofit company, as governed by section 501(c)(3) of the Internal Revenue Code, CAES will initially operate as an internal INL organization staffed with representatives from the INL, universities, and industry. As a nonprofit company, CAES will function as a joint institute between the INL, Idaho State University, Boise State University, and the University of Idaho.

This Program Plan serves as the guiding document for the development and management of CAES and describes the implementation strategies being employed to formulate and subsequently operate CAES. The organizational structure, including collaborative partners, program elements, the development schedule, and the business model, are also presented. The progress of CAES will be measured against performance metrics, which will be reported at an annual meeting and published in an annual report. This Program Plan will be reviewed annually and modified as necessary.

Programmatic goals are being established to guide CAES towards achievement of its vision of advancing energy-related research, education, training, and policy. CAES will facilitate the collocation and collaboration of Government-University-Industry energy-related interests by developing a fully functional nuclear education and research user-facility by 2008. CAES will enhance nuclear educational opportunities by creating a bridge between Idaho, national, and international universities and the INL.

Collaborative and collocated centers, established in association with CAES, will serve as key implementation partners. These centers will focus resources in critical energy areas and will partner with CAES researchers and staff. In this manner, CAES will serve as the hub for a wider network of Idaho, regional, and national universities; private industry; and other associated institutions. CAES will form collaborative arrangements with these various institutions to share resources, equipment, and technical staff.

Three Phases have been defined for the establishment of CAES. The initial activities of CAES, Phase 1-CAES Formulation (2005-2008), involve the establishment of key partnerships and collaborations, infrastructure development, and beginning the process of revitalizing nuclear science and engineering education and research. During Phase 2-CAES Implementation (2008-2010), CAES will expand this revitalization effort through additional technical activities and collaborations. CAES will be organized as a separately incorporated, nonprofit company and will seek tax-exempt status under section 501(c)(3) of the Internal Revenue Code. Phase 3-CAES Operations represents the long-term operating position of CAES. This Phase will be characterized by sustainable programmatic activities, publications 
achieving international impact and recognition, distinctive research signatures, established training programs, and policy studies together with a wide range of education and outreach activities developed in partnership with the Idaho University Consortium (IUC), the National University Consortium (NUC), and the INL.

The Center has achieved a number of significant activities to date towards fulfillment of Phase 1 objectives. The first Director for CAES, Dr Leonard J. Bond, was appointed February 1, 2005. The Secretary of Energy, Samuel Bodman, formally inaugurated the CAES program on June 1, 2005. The core administrative capabilities of CAES and the CAES Steering Committee have been established, and the CAES senior leadership team is being recruited. In cooperation with the INL, the IUC, and the NUC, CAES is in the process of establishing the necessary legal framework between affiliate institutions to streamline and stimulate transdisciplinary interaction and technical collaboration.

Idaho's educational opportunities have already been expanded as the relationship between CAES and its university consortia and affiliate network continue to progress. CAES supported the six-week program for the $1^{\text {st }}$ World Nuclear University Summer Institute held in Idaho Falls, ID, during the summer of 2005. 77 Fellows from 33 countries attended the Summer Institute. The $2+2$ Program in undergraduate nuclear engineering was initiated Fall 2005 with six juniors enrolled. INL will supply adjunct professors to teach courses as needed and CAES is working to arrange six-month INL "practicum" assignments for the $2+2$ participants. A CAES Scholars Program has helped align INL research needs with appropriate graduate student support, and at the present time, seven full-time nuclear engineering graduate students from ISU are being wholly supported by INL research. A bilateral relationship is being developed with the Dalton Nuclear Institute (DNI), University of Manchester, UK. DNI has 12 UK university partners. This relationship will become the first of several arrangements that form an "international university network" engaged in nuclear and related energy education and research programs that will support the international Gen IV program.

A key element enabling the collocation of government, university, and industry researchers and resources is the future CAES user-facility. A partnership between the State of Idaho, the IUC, and BEA is finalizing construction plans for this facility, which is anticipated to be completed by 2008 . When completed, this facility is expected to encompass $50-60,000 \mathrm{ft}^{2}$ of which half is expected to be laboratory space and will house a total of 175 people, including faculty, researchers, staff, and students.

In the course of normal operations, CAES will generate revenue from research, policy studies, and training programs and will incur personnel and other operating costs in support of its employees, resources, and facilities. A business model, including revenue, cost, and staff projections is presented in this Plan. These projections remain consistent with the DOE Field Work Proposal, dated March 9, 2005, and other INL planning documents. Several significant risks (programmatic, infrastructure, legal, and financial) have been identified that could adversely impact the execution of this Program Plan. This Plan discusses these risks and presents proposed mitigation actions, which will minimize or neutralize the identified risks. 


\section{CONTENTS}

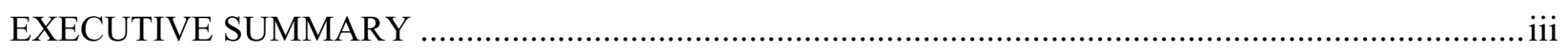

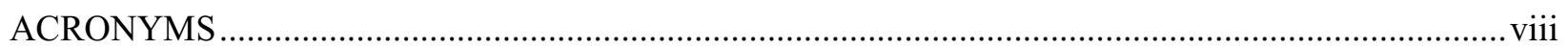

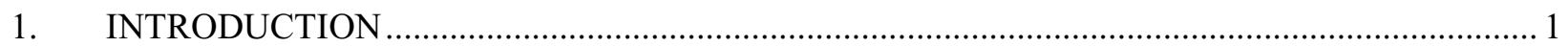

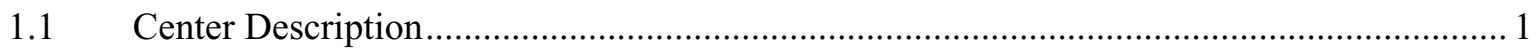

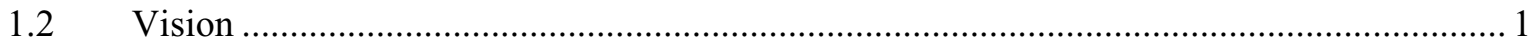

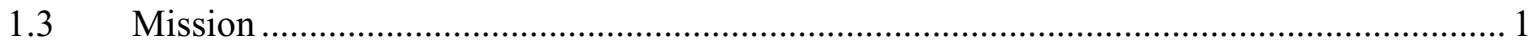

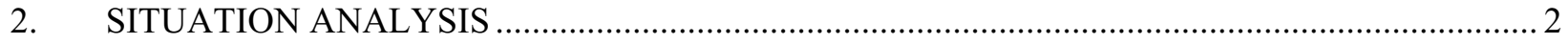

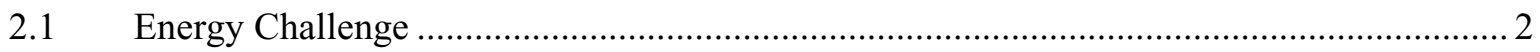

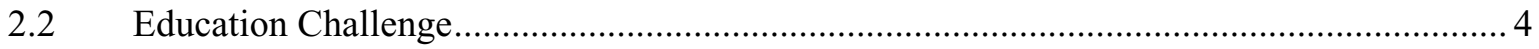

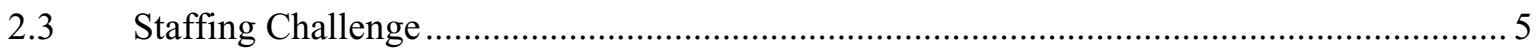

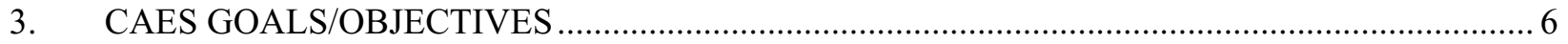

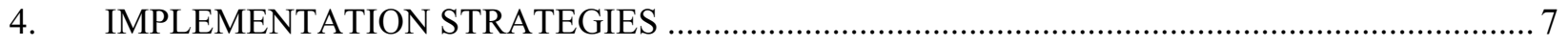

4.1 Phase 1 - CAES Formulation (2005-2008) ............................................................... 7

4.2 Phase 2 - CAES Implementation (2008-2010) ....................................................... 18

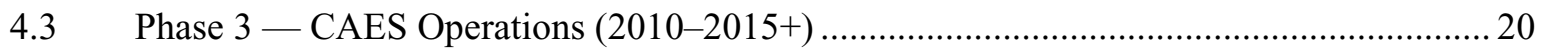

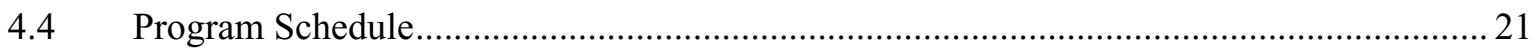

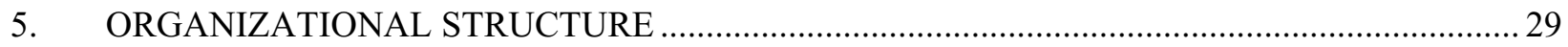

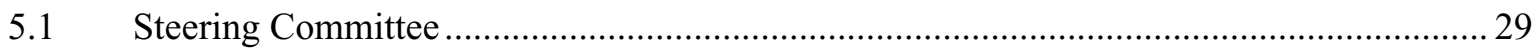

5.2 Executive Advisory Committee (Board of Governors) .................................................. 30

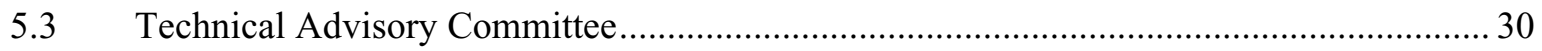

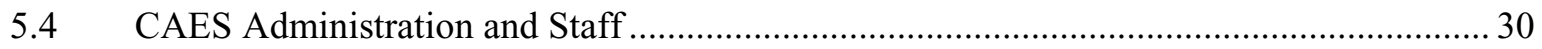

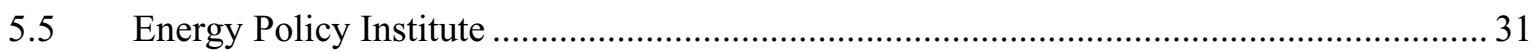

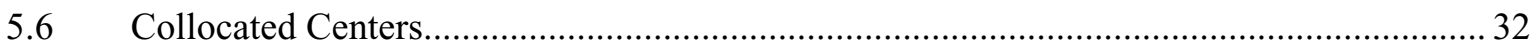

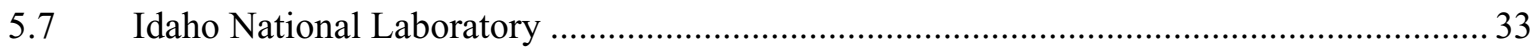




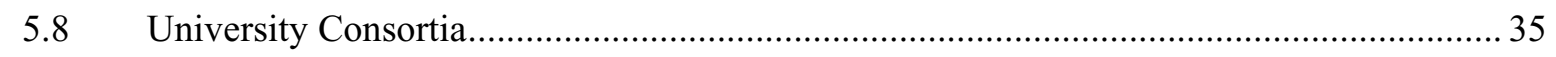

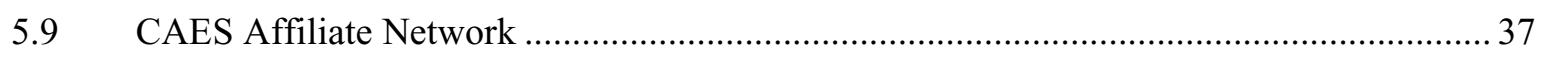

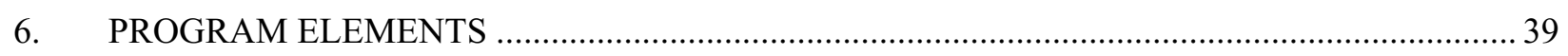

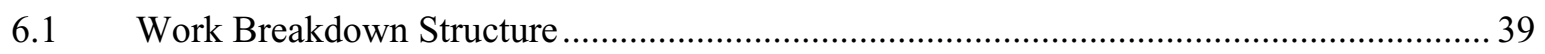

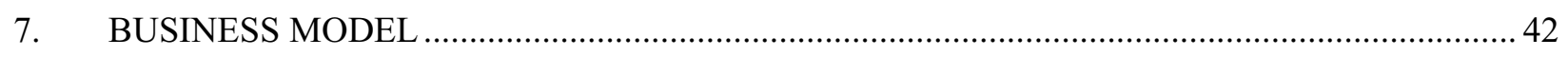

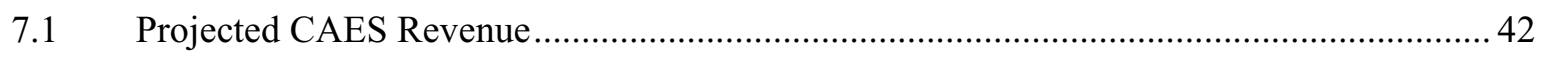

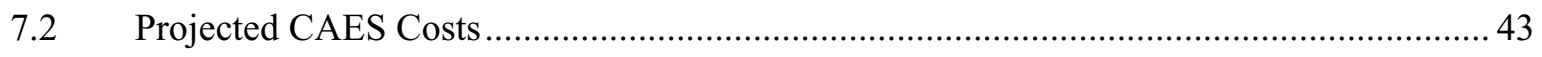

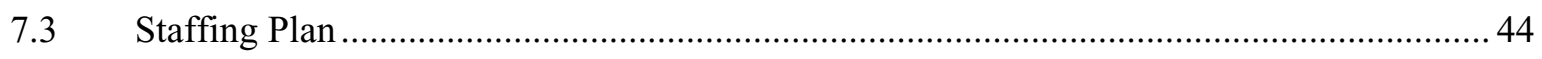

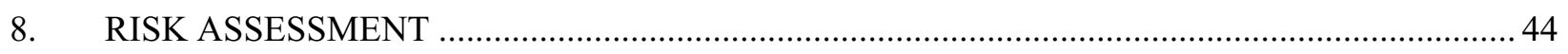

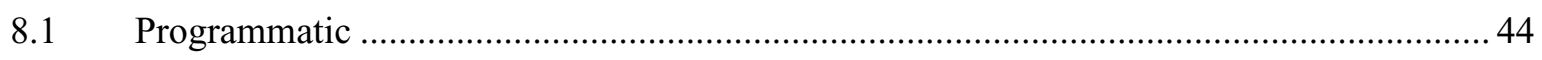

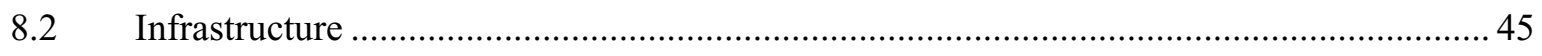

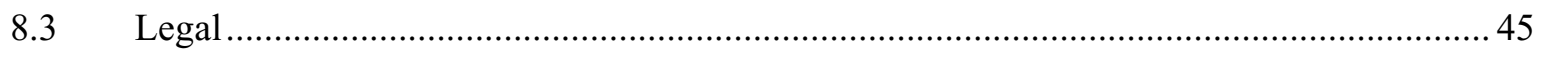

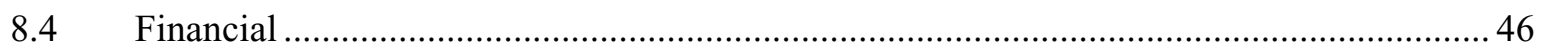

9. ENVIRONMENTAL, SAFETY \& HEALTH CONSIDERATIONS …......................................... 47

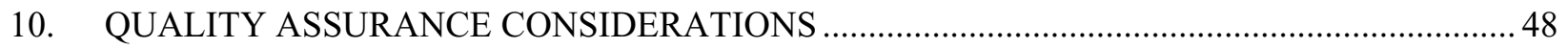

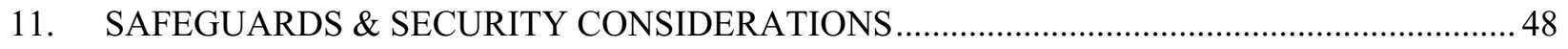

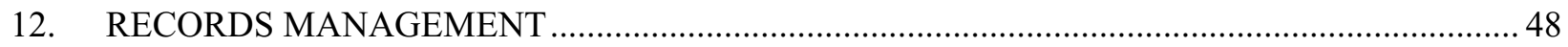

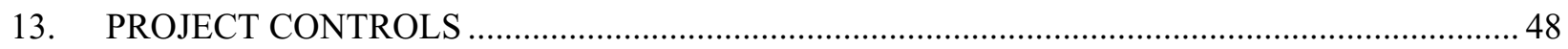

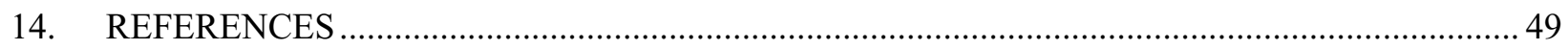

\section{FIGURES}

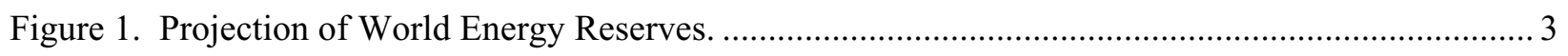

Figure 2. U.S. Current Electricity Generation. .............................................................................. 4

Figure 3. Phased Development of the Center for Advanced Energy Studies. ........................................ 7

Figure 4. Secretary of Energy, Samuel Bodman, formerly inaugurating CAES. …............................... 8

Figure 5. Conceptual Illustration of the Future CAES Facility. ......................................................... 17 


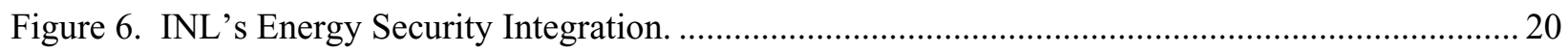

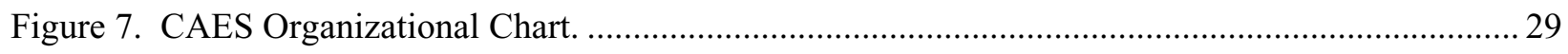

Figure 8. A 3-Dimensional Simulation of Heat Distribution in ATR ...................................................... 32

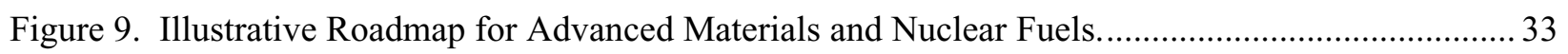

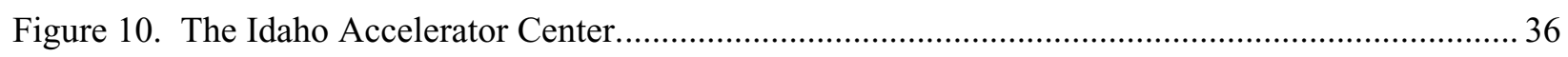

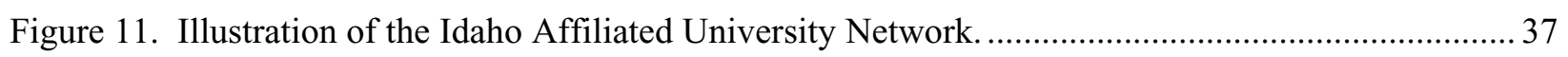

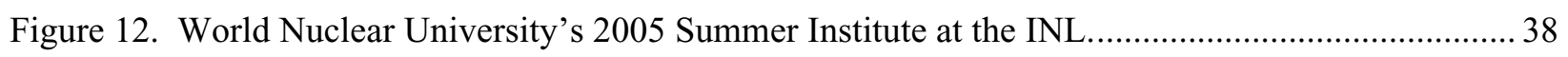

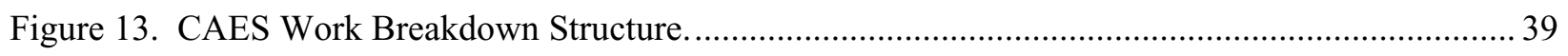

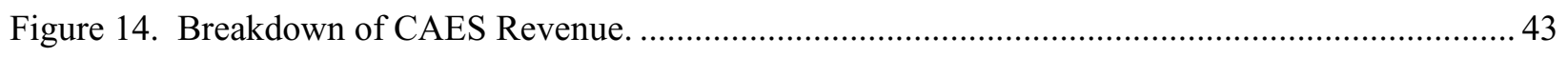

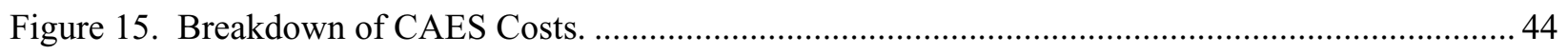

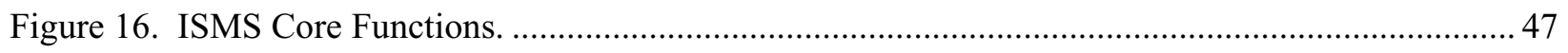




\section{ACRONYMS}

ACE

ATR

BEA

BSU

CAES

CAMS

CNFMR

CNSDA

CRADA

CSNR

DNI

DOE

DOE-ID

EITC

EPI

EPRI

ES\&H

ESH\&Q

ETRP

FTE's Full-time Equivalents

GIF

HUD

IAC

IAEA

IAUN

INL

INPO

INSE

IRS

ISMS

ISSM

ISU

IUC

MFC

MIT

MOA

MOU

Department of Energy
Academic Centers of Excellence

Advanced Test Reactor

Battelle Energy Alliance, LLC

Boise State University

Center for Advanced Energy Studies

Center for Advanced Modeling and Simulation

Center for Nuclear Fuels and Materials Research

Center for Nuclear System Design and Analysis

Cooperative Research and Development Agreement

Center for Space Nuclear Research

Dalton Nuclear Institute

Department of Energy, Idaho Operation Office

Eastern Idaho Technical College

Energy Policy Institute

Electric Power Research Institute

Environmental, Safety \& Health

Environmental, Safety, Health \& Quality

INL Education, Training and Research Partnerships Educational Program

Generation IV International Forum

U.S. Department of Housing and Urban Development

Idaho Accelerator Center

International Atomic Energy Agency

Idaho Affiliated University Network

Idaho National Laboratory

Institute of Nuclear Power Operators

Institute of Nuclear Science and Engineering

Internal Revenue Service

Integrated Safety Management System

Integrated Safeguards and Security Management

Idaho State University

Idaho Universities Consortium

Materials and Fuel Complex

Massachusetts Institute of Technology

Memorandum of Agreement

Memorandum of Understanding 
NASA National Aeronautics and Space Administration

NEA Nuclear Energy Agency

NEI Nuclear Energy Institute

NSF National Science Foundation

NSF I/U CRC NSF Industry-University Cooperative Research Center

NSSTC National Space Science Technology Center

NTEC Nuclear Technology Education Consortium

NUC National University Consortium

QA Quality Assurance

R\&D Research and Development

RTC Reactor Technology Complex

TPE Task Proficiency Evaluation

UI University of Idaho

USRA Universities Space Research Association

WANO World Association of Nuclear Operators

WBS Work Breakdown Structure

WNA World Nuclear Association

WNU World Nuclear University

WSERC Western Strategic Energy Research Center

WSU Washington State University 



\section{Center for Advanced Energy Studies (CAES) Program Plan}

\section{INTRODUCTION}

This Program Plan serves as the guiding document for the development and management of the Center for Advanced Energy Studies (CAES) and presents the current implementation strategy. The strategy will coordinate the Center's evolution to the self-sustaining and enduring world-class entity as directed and envisioned by the U.S. Department of Energy (DOE).

This document represents a 5-year plan during which time CAES will progress from its current status as an "Initiative" of the Idaho National Laboratory (INL) to that of an independent, nonprofit entity by the year 2010 . The planning activities also include the option of an accelerated schedule (currently under evaluation) that could potentially move CAES to a separately incorporated, nonprofit company by 2008. This Plan also presents the 10-year end-state vision (a recognized world-class advanced energy organization) for CAES as well as the strategies to achieve this vision.

\subsection{Center Description}

The Center will be an academic and research institution in which the INL; the DOE; Idaho, regional, and other national universities; and the international community cooperate to conduct energy-related research, classroom instruction, technical training, policy conceptualization, public dialogue, and other events.

Although ultimately operating as an independent, nonprofit company, as governed by section 501(c)(3) of the Internal Revenue Code, CAES will initially operate as an internal INL organization staffed with representatives from the INL, universities, and industry.

Collaborative and collocated centers, established in association with CAES, will serve as implementation partners to focus resources in critical energy areas and partner with CAES researchers and staff. As such, CAES will serve as the hub for a wider network of Idaho, regional and national universities; private industry; and other associated institutions that will form collaborative arrangements to share CAES resources, equipment, and technical staff.

\subsection{Vision}

\begin{tabular}{l|l}
\cline { 2 - 2 } \multicolumn{1}{l|}{$\begin{array}{l}\text { By 2015, } \\
\text { CAES will } \\
\text { become a } \\
\text { world-class, } \\
\text { advanced- } \\
\text { energy }\end{array}$} & \multicolumn{1}{c}{$\begin{array}{c}\text { World-Class } \\
\text { Organization } \\
\text { organization } \\
\text { with an }\end{array}$} \\
emphasis on & $\begin{array}{l}\text { recognized by its peers, } \\
\text { competitors, sponsors } \\
\text { and the public as being } \\
\text { among the world's best }\end{array}$ \\
nuclear energy & in a particular field. \\
and recognized for contributions to energy \\
research, policy studies, and the revitalization of \\
nuclear education. CAES will also train a diverse \\
science and engineering workforce.
\end{tabular}

As a central element of the INL transformation strategy, CAES will engage in workforce reinvigoration, development of a workforce pipeline enabling strategic hiring, workforce diversification, and culture change. CAES will develop research partnerships that provide its university network with enhanced access to INL facilities.

\subsection{Mission}

The CAES mission is to address critical science and engineering issues that will help resolve the grand challenges associated with providing an appropriate mix of energy technologies needed to address critical U.S. and global energy needs. Although CAES will have an emphasis on nuclear energy, it will also address other energy areas that are critical to ensuring U.S. 
energy security, including affordability, limited environmental impacts, and leadership in the global energy arena. Energy technologies to be addressed include those for nuclear, hydrogen, and fossil fuels (coal, oil, and gas) and the full spectrum of renewable energy sources.

The Center will develop its research agenda to advance the education of the next generation of scientists and engineers and provide them with skills and experience needed to address critical workforce needs. CAES will engage in long-term, university-based research activities and host a range of national and international events.
Activities are being designed to facilitate an informed debate, which will address the questions and issues concerning the best energy technology mix necessary to meet U.S. and global needs. This dialogue will present the facts about the benefits and risks of nuclear energy in the world energy and environmental debate, and conduct a wide range of academic and public education activities.

The Center will advance academic capabilities by fostering collaborations and interdisciplinary studies and by making its research and development facilities and those of the INL available to a network of universities.

\section{SITUATION ANALYSIS}

Critical energy issues, highlighted by recent world events including passage of the most recent U.S. Energy Policy Act (2005), signify a need for action. The need for CAES, in association with the INL, to address key energy challenge issues is evident given the current U.S. and global energy situation, U.S. science and engineering educational challenges, and the combination of current energy industry workforce demographics and future workforce projections.

\subsection{Energy Challenge}

World energy demands are at an all time high. The world's population, over 6 billion people, uses almost 400 quadrillion BTU of energy annually. This is roughly equivalent to 180 million barrels of crude oil per day. These energy demands are expected to triple by 2050 as a result of several factors.

First, as the population of the world continues to increase, the energy demands are projected to further rise. Global population is expected to increase to over 9 billion people during the current century. Economic industrialization occurring throughout the 3rd world further adds to the global energy demands. Globally, about $1 / 4$ of the land surface is devoted to agriculture and $1 / 4$ is forested. At present, as population grows in general terms, land is converted from forest to food production, and productive agricultural land is being lost to urban growth. Additionally, meeting these energy demands is further compounded by resource depletion and environmental concerns, such as climate change, land use change, water resource availability, and global sustainable development efforts.

The United States accounts for approximately $5 \%$ of the global population and approximately $25 \%$ of the world's energy consumption, or approximately 100 quadrillion BTU each year. The United States requires secure, sustainable, and affordable energy supplies that can be achieved with limited environmental impact. In 1997, a report to the President reviewed federal energy research and development challenges (Gibbons, 1997). This report identified that the United States faces major energyrelated challenges as it enters the $21^{\text {st }}$ The world is not running out of energy, but it is running out of the types of hydrocarbon-based energy that are currently the basis for global energy delivery.

Century.

The global energy resources currently used are finite. Achieving a sustainable energy system is essential to meeting both U.S. national needs in terms of energy security and economic stability, as 
well as global energy demands in ways that avoid wars and economic instability (Tester et al., 2005).

Numerous publications present future energy scenarios. Some reports state that global production of sweet light crude oil will peak in 2005-2006 and that global oil production could be down by $75 \%$ within 30 years. Other reports are more optimistic and assume that alternative hydrocarbon resources, including tar sands and gas hydrates, will be utilized and that no problems will be encountered for many decades. One example of estimates for future global energy reserves based on one of many global energy use scenarios is shown in Figure 1. This scenario assumes the rapid development and deployment of advanced nuclear energy technologies used together with a closed nuclear fuel cycle.

The world is not running out of energy, but it is running out of the types of hydrocarbon-based energy that are currently the basis for global energy delivery. Two critical challenges are (a) developing an integrated and coordinated approach - at the global level - that enables an orderly transition to an advanced energy future that is sustainable, affordable, and has limited environmental impact and that can meet growing global energy demands, and (b) providing the critical technologies to meet the global energy future, whether it be the hydrogen economy that some envision, advanced nuclear energy, and/or new synthetic hydrocarbons together with clean coal and renewable energy technologies.

In the long-term, one vision is of a world transportation system powered by hydrogen and nuclear systems providing electricity via fission and fusion and integrated closed fuel cycles. A closed fuel cycle with recycling of spent nuclear fuel offers an energy system with significantly reduced environmental impact, reduced residual waste volume and isotope life, and zerogreenhouse gas emissions. Full implementation of such energy systems is several generations in the future. Generation IV and advanced nuclear energy sources are not expected to be commercially available before mid-century.

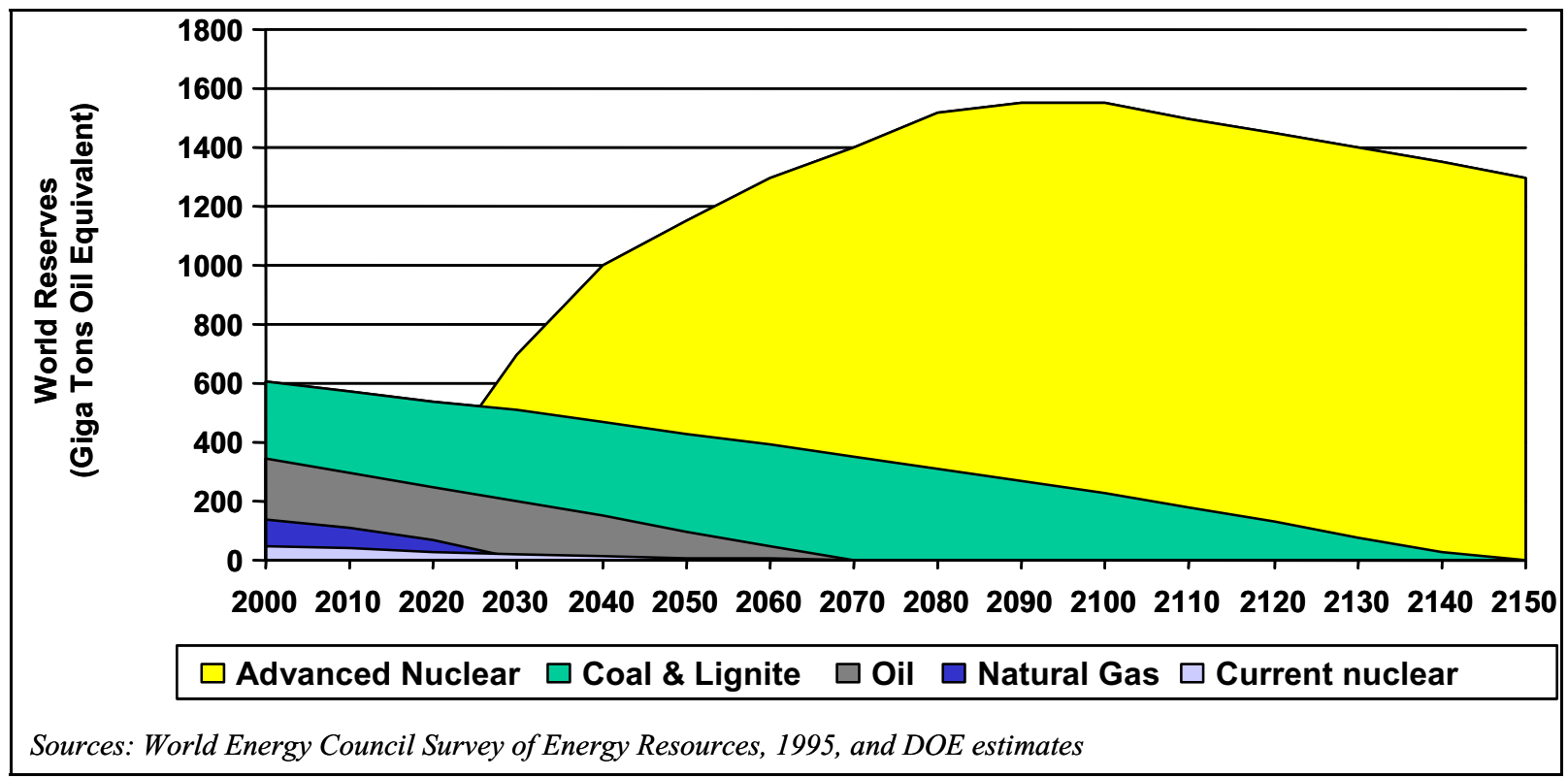

Figure 1. Projection of World Energy Reserves.

Over the next fifty years, the U.S. and the global population will need all current (Figure 2) and envisioned energy technology systems if global energy demand is to be met. CAES will play a vital role by facilitating integration of the necessary science, engineering, and policy to 
create a world-class center of thought leadership and science and technology delivery, recognized for addressing some of these critical science and energy policy issues through its established and distinctive signatures.

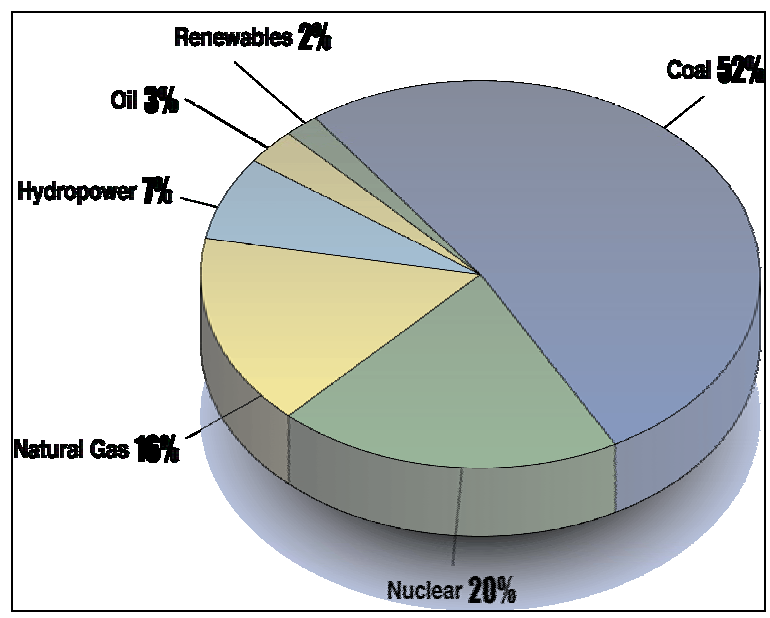

Figure 2. U.S. Current Electricity Generation.

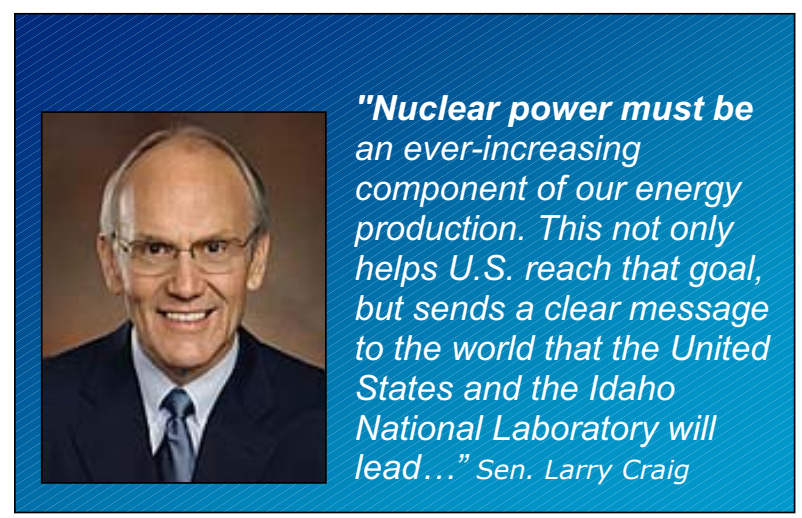

\subsection{Education Challenge}

A series of recent studies discuss the nuclear education and staffing challenge that is facing the United States and other nations. These studies highlight the need to rebuild critical skills that will be necessary to meet the needs of the nuclear research and energy industry (NETF, 2005; Wogman et al., 2005). For example, Corradini et al., (2003) report that "Over the past decade the number of nuclear engineering programs in the United States has declined by half (from 80 to 40), the number of university research and training reactors by two-thirds (from 76 to 28), and total enrollments have dropped by almost $60 \%$ (from 3,440 to 1,520)" (Corradini et al., 2003).

Several studies report B.S. and M.S. graduates in nuclear engineering number about 200 per year (Magwood, 2002; Corradini et al., 2003).

Magwood cites a nuclear engineering department report (Was and Martin, 2000) that states demand is for $\sim 600$ graduates annually and rising, and expected to rise further. Further, Magwood reported that total national undergraduate enrollment in nuclear engineering was just under 1,000 in 2001 , down from a level of $\sim 1,500$ that persisted through the 1980s and until 1995.

Recent data regarding nuclear engineering degrees is available from the Oak Ridge Institute for Science and Education (ORISE, 2005). This information shows:

- B.S. level - 219 graduates in 2004, as compared with 222 in 1998 and a low of 120 in 2001.

- M.S. level - 154 graduates in 2004, as compared with 160 in 1998 and a low of 130 in 2002.

- Ph.D. level - 75 graduates in 2004, as compared with 98 in 1998 and a low of 67 in 2002.

While enrollment in nuclear engineering programs appears to be increasing slightly from the low seen in $\sim 2002$, it has returned only to the level of the late 1990's. The demand for nuclear engineers still exceeds the supply. Enrollments are very much lower than will be needed to support a nuclear resurgence. There are also significant challenges in the areas of health physics, actinide chemistry, and related engineering and science disciplines.

The current numbers of students in the pipeline are a particular concern when set in the context of surveys showing that approximately $75 \%$ of nuclear personnel currently employed within the DOE national laboratories will be eligible to retire by 2010 (Wogman et al., 2005).

The particular challenges faced in nuclear and related topics are not unique. Within the United States, there is a lack of talent entering the general 
science and technology workforce pipeline (BEST, 2004). Recent reports indicate that only $26 \%$ of U.S. high school graduates were considered to be qualified for entry into science or engineering programs in further and higher education. The numbers of students entering science and engineering as a percentage of students is a much smaller fraction than those in countries with which the United States has to compete. A further issue is the reduction in numbers of trained science and engineering graduates entering and remaining in the United States and at least in some critical areas reductions in numbers of foreign students in U.S. programs. The ability to provide adequate numbers of educated and trained staff to meet U.S. energy industry needs can be expected to be a major and growing issue over the next decade.

\subsection{Staffing Challenge}

The educational situation contributes directly to a growing nuclear engineering and related science, engineering, and technical staffing challenge. The "human element" in the nuclear power infrastructure has been identified by the Secretary of Energy Advisory Board's Nuclear Energy Task Force (NETF) as a key area that must not be neglected (NETF, 2005).

The BEST Report noted that $25 \%$ of U.S. scientists and engineers will reach retirement age by 2010 . The situation, specifically in nuclear, is even more stark with approximately $75 \%$ of nuclear personnel currently employed within the DOE national laboratories eligible to retire by 2010. Likewise, approximately $40 \%$ of the current technician workforce is also expected to retire in the next 5-7 years. Many utilities, especially in the commercial nuclear utility ranks, are being forced to coordinate their outages due to insufficient supplemental staff. In fact, some utilities have been placed in a position of reducing power levels so they can continue to operate within their safety basis until an outage can be arranged.
The United States is not alone in this staffing challenge. The Organisation for Economic Cooperation and Development (OECD) has described the global nuclear and related skills shortage. As they point out, meeting the global demand for a nuclear workforce, while at the same time addressing security issues, further complicates the personnel issue (NEA-OECD 2000a). With growing competition in the labor market, an additional concern in staffing the energy sector is that replacement workers are expected to have higher levels of qualifications and training and will experience a higher turnover rate than the current experienced staff.

As such, the continuous people pipeline needed to get new workers into the industry (fossil, nuclear, alternative, etc.) is currently insufficient to meet the needs in energy production, transmission, and distribution given the retirement picture and competition for qualified workers. National and industry-wide approaches are needed to rectify this issue. This is anticipated to result from an increased demand for trained experts during the impending workforce shortage.

The NETF recommended to the Secretary of Energy to address this workforce issue and "establish strong programs of undergraduate, graduate, and post-doctoral fellowships or traineeships in the physical sciences and engineering. One important aspect of these efforts is the development of the workforce that is essential for the resurgence of nuclear technologies" (NETF, 2005).

The Center, together with partnering universities, is seeking to work together with INL and DOE to address this identified need for nuclear engineering and energy-related professional education and related training (B.S., M.S., Ph.D., and post-doctoral education and training). At the technician level, CAES is targeting solutions where standardized, industrydriven curricula can be defined, developed, and packaged for uniform use throughout the country. 


\section{CAES GOALS/OBJECTIVES}

To achieve its vision of being a recognized world-class organization, CAES will meet the following programmatic goals and objectives.

1. CAES will advance energy-related research, education, training, and policy.

a. CAES will facilitate research that is critical to resolving the technical challenges associated with achieving a mix of advanced energy sources.

b. CAES will advance academic expertise and capabilities in energy science, technology, and policy and do so in Idaho, nationally, and internationally.

c. CAES will facilitate the training of the next generation of nuclear scientists, engineers, and technicians.

d. CAES will advance sound energy policy leading the United States towards improved energy security.

2. CAES will develop a fully functional, nuclear education and research user-facility by 2008 .

3. CAES will enhance Idaho nuclear educational opportunities.

a. CAES will create a bridge between Idaho, national, and international universities and the INL.

b. CAES and INL research and development capabilities and facilities will be available to a network of universities. c. CAES will aid the Idaho Universities in becoming world-class centers for nuclear research and education.

4. CAES will facilitate the collocation and collaboration of Government-UniversityIndustry energy-related interests.
a. CAES will have collocated and collaborating Centers.

5. CAES will be a self-sustaining and internationally recognized advanced energy organization by 2015 .

a. CAES will develop distinctive technical signatures in energy-related research, education, training, and policy.

b. CAES will be a joint institute of the INL, Idaho State University (ISU), Boise State University (BSU), and the University of Idaho (UI).

c. CAES will serve as the hub of a network of INL-affiliated universities initially involving Massachusetts Institute of Technology, North Carolina State University, the Ohio State University, Oregon State University, and the University of New Mexico.

d. CAES will continue to engage a wider network of partnering organizations (e.g. Dalton Nuclear Institute, University of Manchester, UK) and will support the international Generation IV network. 


\section{IMPLEMENTATION STRATEGIES}

While CAES will ultimately operate as an independent, nonprofit company, it is recognized that program development and certain legal and financial requirements must first be satisfied. As such, the evolution of CAES is planned to involve three distinct phases.

The initial activities of CAES, Phase 1CAES Formulation (2005-2008), involve the establishment of key partnerships and collaborations, infrastructure development, and beginning the process of revitalizing nuclear science and engineering education and research. During Phase 2-CAES Implementation (20082010), CAES will be organized as an independent, nonprofit entity and will operate consistent with IRS requirements so as to obtain tax-exempt status [i.e. 501(c)(3)]. This Phase will continue revitalization efforts by expanding technical activities and collaborations. Finally, Phase 3CAES Operations (2010-2015+) represents the long-term operating position of CAES that will attain world-class recognition by 2015 . This Phase will be characterized by publications achieving international recognition in education, research, training, and policy analysis.

Figure 3 illustrates this evolution of CAES. Specific elements to be emphasized within each Phase of CAES are discussed in the following sections.

\subsection{Phase 1 - CAES Formulation (2005-2008)}

CAES has achieved a number of significant accomplishments during fiscal year 2005. A summary of these activities is presented here along with key activities currently under way, as well as those that will be completed during the remainder of Phase 1.

\subsubsection{CAES Inauguration}

The Secretary of Energy, Samuel Bodman, formerly inaugurated the CAES program on June 1, 2005 (see Figure 4) amidst a host of other dignitaries. "The goal here in Idaho is to become the premier facility for nuclear energy in the country."

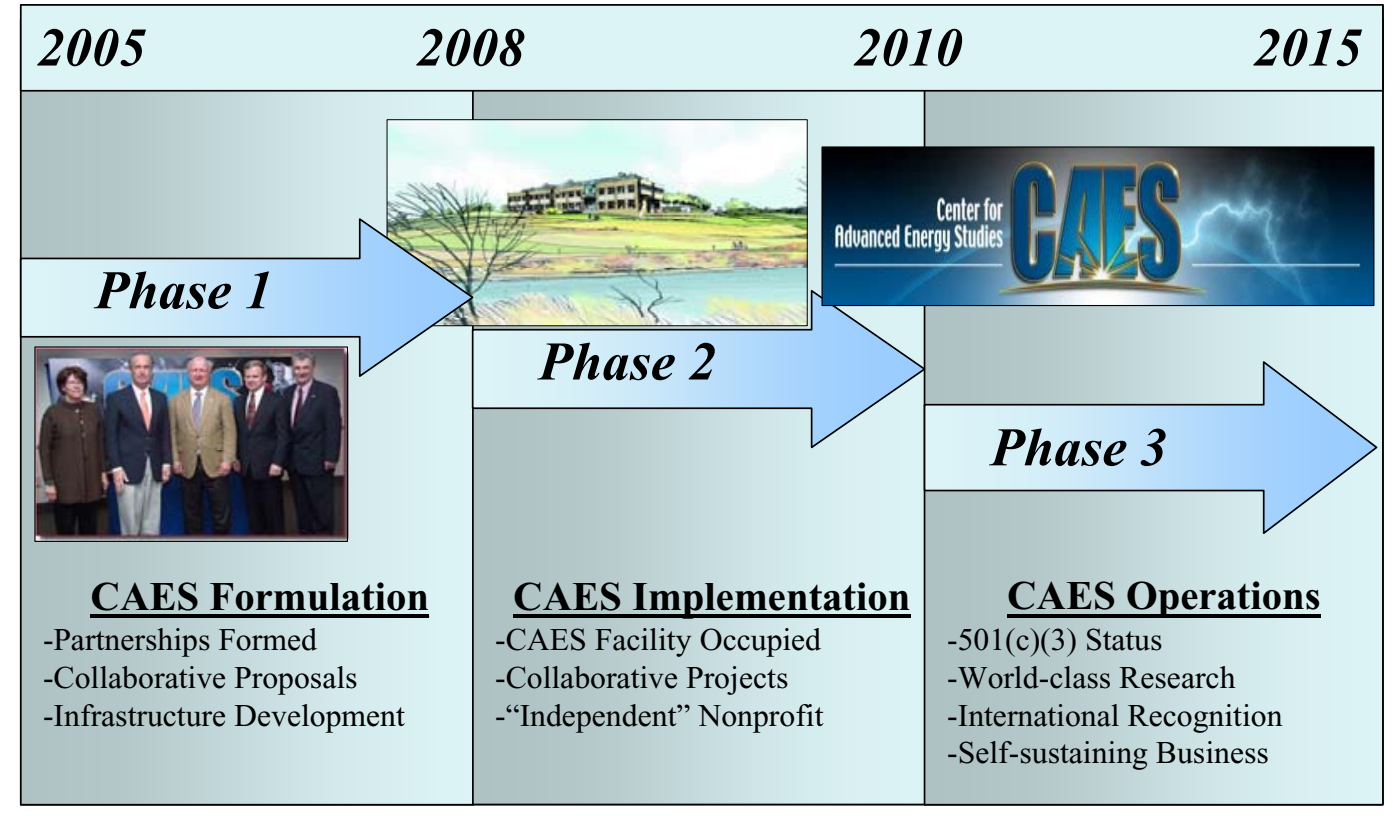

Figure 3. Phased Development of the Center for Advanced Energy Studies. 


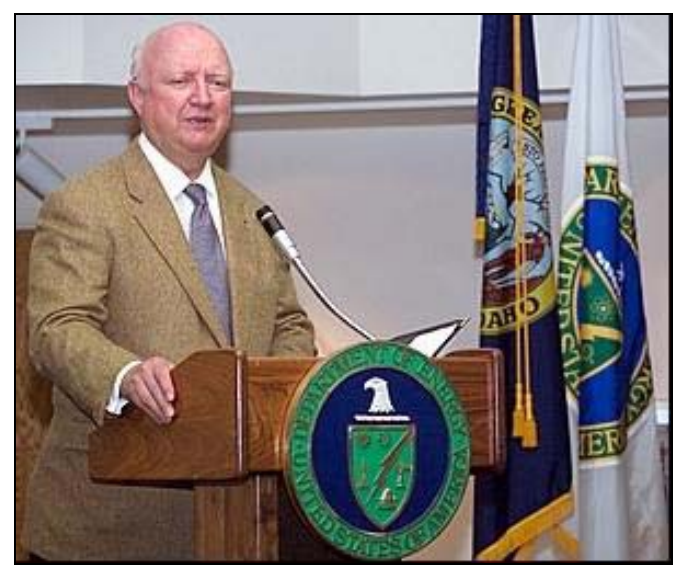

Figure 4. Secretary of Energy, Samuel Bodman, formerly inaugurating CAES.

\subsubsection{Establishment of a Central CAES Organization}

During Phase 1, the core administrative capabilities of CAES are being established. A number of administrative elements of CAES were established during FY-05, and several additional elements are being completed during FY-06 to facilitate the advancement of CAES and implementation of a full spectrum of programmatic activities.

This central CAES organization consists of the enabling functions of CAES and is represented in the Work Breakdown Structure (see Figure 13, under Section 6.1) as the Administrative and Collaborative Relations work elements. The establishment of these functions will facilitate and coordinate the broader technical and programmatic elements of CAES.

\section{Strategic Appointments/Hires}

The CAES senior leadership team was partially established during FY-05. Dr. Leonard J. Bond was appointed as the first Director for CAES effective February 1, 2005. The UI and ISU University have both appointed Dr. Bond to be an Affiliate Faculty in the Department of Physics, and $\mathrm{BSU}$ is in the process of making a similar appointment.

Dr. Michael Lineberry, holding a joint appointment with ISU, has been appointed as the Associate Director of CAES for Education. Mr.
Richard Holman is the Acting Manager for Training and Workforce Initiatives.

Several remaining members of this team will be identified during FY-06. Appointments for the positions of Associate Director for Research and Associate Director for Energy Policy will be made following national searches coordinated by representatives of the INL and the IUC partners.

The CAES Board of Governors will be formalized as an "Executive Advisory Committee" in FY-06. This group will become a formal Board when CAES becomes a nonprofit entity and will provide oversight of CAES activities. The organizational representation of this group has been determined. During FY-06, specific representatives from these organizations will be selected to form this Committee.

The CAES Executive Advisory Committee will establish the Technical Advisory Committee during FY-06. The CAES Technical Advisory Committee will be comprised of technical experts selected from the national laboratory complex, academia, and industry. This Committee will provide the necessary independent technical guidance to the CAES Executive Advisory Committee (Board of Governors) and to the CAES senior leadership team.

It is recognized that during FY-06 program development activities are needed to enable a programmatic and business base to be established for CAES, and that the activities will utilize a combination of INL and university staff on an asneeded basis. The CAES leadership, the Steering Committee, and the Executive Advisory Committee will coordinate these business development activities.

A process to identify and appoint CAES Fellows will be established during FY-06. It is planned that at least five Fellow positions will be filled by FY-07. These staff will be instrumental in establishing, implementing, and achieving the technical and programmatic vision of CAES. A competitive selection process will be implemented to identify and select appropriate candidates for these positions. Candidates will be sought from within the INL, the IUC, and the NUC universities. It is anticipated that these fellowship 
appointments will initially have a duration of 12 years.

The Center, in cooperation with the INL and the Idaho Affiliated University Network (IAUN), is in the process of establishing the necessary legal framework for (a) a Memorandum of Agreement (MOA) to establish CAES as a joint institute between INL, ISU, UI, and BSU; (b) a draft lease for the new CAES facility; (c) a joint appointment/affiliate staff program; and (d) the IAUN.

The INL/CAES-University "Joint Appointments" process will stimulate transdisciplinary interaction and foster technical collaboration. This will facilitate appointment of the two remaining CAES Associate Director positions, as well as the establishment of CAES Faculty Affiliates and INL-Staff/CAES Affiliates during 2006.

\section{Expedite Establishment of Nonprofit Entity}

To best facilitate a collaborative GovernmentUniversity-Industry partnership and to diversify funding opportunities, CAES is expected to operate as a nonprofit entity and joint institute. Such a classification is important because it permits CAES to seek unique funding opportunities that are not available to the INL or in some cases universities, it establishes CAES as an independent "non-government" organization, and it ultimately provides financial incentives in terms of tax-exempt status.

The nonprofit transition is complex and is currently expected to take at least four years to ultimately obtain tax-exempt status under section 501(c)(3) of the Internal Revenue Code. CAES will further consider the legal framework as well as an accelerated schedule for establishing a separate nonprofit company entity. This transition and the associated business model appear dependent on the completion and occupation of the new CAES facility (planned for 2008).

\section{Strategic Partnerships}

A key implementation strategy is the establishment of strategic partnerships. Strategic partners, identified in Section 5, will work in a collaborative manner with CAES. In some cases, organizations will be collocated with CAES to enhance interactions.

This broader affiliate CAES organization will involve various types of relationships and partnerships. It is envisioned that some partners will bring ongoing independent programs while others will seek to form interdisciplinary collaborative teams that pursue and initiate new programs within CAES.

Given this range of expected interaction, CAES will use a variety of mechanisms to establish and maintain these strategic partnerships, including formal contractual and financial agreements/commitments, cost-sharing arrangements, cooperative research and development agreements (CRADA), and informal MOAs and Memoranda of Understanding (MOU). The INL Technology Partnerships organization and General Counsel will be instrumental in assisting CAES in the establishment of these various arrangements.

\section{Strategic Planning}

As CAES moves forward in attracting and organizing the numerous collaborators and development partners, it will continue to shape its technical programs through integrated strategic planning. These efforts will allow CAES to develop its own unique contributions, which align with the three Idaho Universities, a proposed Idaho Fuel Cycle Academic Center of Excellence, the five NUC Academic Centers of Excellence (ACEs), the four collocated Centers and the capabilities of the INL.

It is also expected that as CAES moves forward in establishing its university network, the five NUC universities will play a critical role in formulating an expanded collaboration network with other organizations, such as the Dalton Nuclear Institute, as well as participants from the International Generation IV countries. It is expected that staff exchanges and joint international programs and partnering will be developed. Given the location and nature of the CAES facility as a university building on university land, this will enable the hosting of foreign nationals that could not easily be accommodated in a DOE facility. 
During FY-06, CAES will develop detailed Technical Agendas for each of its program areas (research, education, training, and policy). These agendas will be integrated into the CAES FY06 Strategic Plan and will include an internal analysis of the "greater-CAES community" in terms of its strengths and weaknesses as well as external constraints in terms of threats (competition) and opportunities (financial and programmatic).

\subsubsection{Expanding Idaho's Educational Opportunities}

Relationships between CAES and its university consortia and affiliate network continue to progress and have already expanded Idaho's educational opportunities. CAES will continue these efforts by establishing an Education Committee, chaired by the CAES Associate Director for Education, which will provide the interface and coordination between INL's Education Programs Office, the partnering universities, and INL's Human Resources Department. This Committee will address how CAES, through the universities, provides a full spectrum of education opportunities, short courses and workshops.

\section{2+2 Program}

The 2+2 Program in undergraduate nuclear engineering, which culminates with a B.S. degree in Nuclear Engineering, was initiated Fall Semester 2005. Six juniors, four from the ISU College of Engineering, and one each from BSU and the UI, are currently enrolled and on schedule to graduate in December 2007. These students are supported with tuition, fees, and a stipend paid as a result of a grant from the AREVA Group $(\$ 50,000)$ "matched" by a DOE Industry Matching Grant Award of $\$ 40,000$.

INL will supply adjunct professors to teach courses as needed. This approach supports the universities and builds the bridge between INL scientists/engineers and the Idaho university community.

The Center is working to arrange six-month INL "practicum" assignments for the $2+2$ participants during the summer-fall semester between their junior and senior years. This is intended to be a special internship in which INL's unique nuclear facilities are made available for laboratory work. Details are being worked out between CAES and INL staff regarding use of the Advanced Test Reactor (ATR) at the Reactor Technology Complex (RTC), and Neutron Radiography Reactor (NRAD) at the Materials and Fuels Complex (MFC).

Idaho State University is working to achieve accreditation of the B.S. in Nuclear Engineering degree by 2008 . The goal is to have the program provide a joint B.S. degree from ISU and the institution that provided the first two years' education. The three College of Engineering Deans of ISU, UI, and BSU are currently preparing this plan, which requires Idaho State Board of Education approval.

\section{Graduate Program}

The graduate curriculum at all three IUC schools is being reviewed to ensure that degree programs meet the needs of the INL. The university community has committed to work with CAES to enhance and expand graduate degree programs and course offerings for academic year 2006-07 to better meet the needs of the new INL and CAES.

The Center is currently arranging for special courses to be taught in highly technical subject areas related to the INL mission. During the summer 2005, this new mechanism for special courses, which includes credit from the IUC universities, was implemented. Dr. Wes Hines of the University of Tennessee taught a Short Course at the Idaho Falls University Place campus during August 2005 entitled, "Empirical Methods for Nuclear Power Plant Process and Equipment Monitoring". Visiting professors Dr. Barry Ganapol, from the Department of Aerospace and Mechanical Engineering, University of Arizona, and Dr. Cassiano R. E. de Oliveira of the Nuclear and Radiological Engineering Program, George W. Woodruff School of Mechanical Engineering, Georgia Institute of Technology, taught the "Advanced Radiation Transport and Shielding" short course. Dr. Ray Berry of the INL taught a 
short course entitled, "Computational Fluid Dynamics."

\section{CAES Scholars}

CAES has already significantly expanded the Idaho universities' participation in INL nuclear energy research. During FY-05, CAES helped align INL research needs with appropriate graduate student support. At the present time seven full-time, traditional nuclear engineering graduate students from ISU are being wholly supported by INL research. This includes five Master's students and two student pursuing Ph.D.'s. CAES is working to increase INL student research support for FY-06 and anticipates that by year's end CAES will have at least 12 CAES Scholars in residence supported by INL.

\section{Distance Learning}

The Center will work with the university network, including both the IUC and NUC, to further develop distant learning opportunities for representatives of all participating institutions. For example, consideration will be given to delivery of technical electives on the Idaho Falls and main Idaho campuses for courses taught at the NUC universities.

\section{Education Resource Network}

The Center will include access to energy education resources from its web site. Working in partnership with the INL, CAES will seek to become a node in an education information network, which includes nuclear and other advanced energy technologies.

\subsubsection{Establishing the Necessary Workforce Training}

The CAES Office of Training and Workforce Initiatives has been investigating and assessing the energy sector workforce situation (Section 2.3). CAES will continue to identify the training elements for which CAES can most productively contribute to improve this situation. Two of CAES' national training efforts will be in the area of energy workforce development and improving the numbers and training of nuclear plant startup engineers.

\section{Energy Workforce Development Initiative}

The CAES Energy Workforce Development Initiative is an effort to improve the pipeline of people into and development of a robust energy sector workforce. This initiative links several federal agencies, the INL, EPRI, private sector industry, and several educational institutions together to resolve a dilemma in the energy industry - the need to identify, train, and develop new maintenance workers and technicians to replace the large numbers of retiring workers across the sector.

This effort builds on current efforts in both the Departments of Labor and Energy that are aimed at a standardized program. CAES and EPRI, using the existing EPRI Task Proficiency Evaluation (TPE) Program coupled with ISU and Eastern Idaho Technical College (EITC) capabilities and coursework, will support the establishment of a national network of community colleges, vocational-technical schools, and tribal education institutes. The result of this effort will be a standardized two-year curriculum delivered by regional institutions. An unsolicited proposal to develop such an approach is being reviewed by the U.S. Department of Labor's Employment and Training Administration.

\section{Startup Engineer Training (CAES Nuclear Energy Resurgence Curriculum)}

The Startup Engineer Training Program is based on the identified needs of industry with regard to the imminent resurgence in nuclear plant construction. It is one element of the CAES nuclear energy resurgence curriculum. With the current focus on expanding the nation's nuclear energy generating capacity it is imperative that the industry has the necessary skills and technical competence to safely and productively undertake system testing and startup activities. Competent "startup" engineers ensure that subsequent plant operations perform safely and efficiently. The activities performed by these engineers can reduce costs by millions and schedules by months. There appears, however, to be a critical shortage of "startup" engineers in the United States. CAES is working to promote a program with industry and regulators that will provide the training and skills 
needed to ensure successful, timely, cost-effective, and safe startups.

The goal of this program is to produce trained construction test and startup engineers with demonstrated knowledge, skills, and attitudes, and industry-wide contacts who will be an asset to their utility, regulatory agency, or vendor during plant startup. It is imperative that the engineers involved in construction, startup testing, and initial operations, particularly those in the ranks of the regulators and utilities, have the necessary skills, technical competence and proficiency.

This CAES program will be an industry-wide integrated training program intended to involve all viable commercial reactor designs, reactor vendors, equipment vendors, architect-engineers (AEs), utilities, regulators, and others. The overall goal is to provide training for the people who will conduct the startups and help them develop their knowledge, as well as their technical and interpersonal skills.

The Center also plans to offer this training to the regulators since a strong nuclear industry requires a knowledgeable and experienced regulatory workforce. Separate regulator-specific sessions will be offered to maintain the necessary distance between regulators and regulated.

\section{International Efforts}

\section{Knowledge Capture/Management}

There are currently no reliable and systematic means for ensuring that the tacit knowledge and skills of the aging workforce are captured and communicated to the remaining workers. CAES is working with industry, the INL, other federal agencies and the international community through the International Atomic Energy Agency (IAEA) to determine an approach to best capture the knowledge of the retiring and departing workforce. The IAEA effort is expected to result in an IAEA TechDoc entitled "Guidance Document on the Preservation (and Enhancement) of Knowledge for Nuclear Power Plant Operating Organizations." Mr. Richard Holman, Acting Manager of the CAES Office of Training and Workforce Initiatives, is an IAEA invited member to this technical committee.

\subsubsection{Research}

As CAES moves to be an enduring and selfsustaining entity it will achieve its business base by establishing a set of distinctive research signatures. These distinctive signatures will be carefully selected and CAES resources will be focused to establish and maintain these signatures.

Business development activities have been initiated during FY-05 and initial proposals have been submitted. Additional activities will be conducted during FY-06. An integrated CAES Strategic Research Plan will be developed during FY-06 and potential funding opportunities will be identified and targeted. Pre-proposal planning activities will be performed so as to position CAES and the affiliated team to prepare and submit proposals with high probabilities of success. In FY-07 a targeted business development strategy will be implemented to capture the necessary research funding for selected programs and CAES affiliated staff.

The Center began in FY-05 to significantly increase involvement of full-time nuclear engineering graduate students doing their research at INL, via INL support, on problems relevant to major INL programs. This program contributes to the revitalization of nuclear engineering in the IUC. The intent is to increase the nuclear engineering student involvement to at least 12 students-in-residence during FY-06 as well as consider non-nuclear engineering opportunities.

To continue to grow the total number of students involved, it is necessary to bring more faculty into roles within INL programs. As such, a pilot program was initiated in FY-05 whereby faculty began working with INL programs via low-cost "mini-grants". It is anticipated that these working contacts will lead to more substantial involvement of the faculty in INL and CAES programs such as expanded involvement of graduate students and joint proposals for new CAES research. The goal for FY-06 is to continue the pilot program with 10 mini-grants.

The Center is an advanced energy Center, not exclusively an advanced nuclear energy Center. Therefore, both nuclear and non-nuclear research 
will be conducted. Topics being considered include:

\section{Nuclear Energy Research}

Although discussions and activities were initiated during FY-05, the process of identifying unique CAES research areas will be expanded during FY-06. CAES will conduct a series of workshops to further refine and develop appropriate research topics given its collective research capabilities (INL, IUC, NUC, etc.). Some initial areas being considered include:

1. International Nuclear Fuel Cycle - The nuclear fuel cycle represents an ideal area of CAES research emphasis. First, it is of vital importance to ensure safeguarding of existing and planned fuel cycle activities. Second, as nuclear power continues to expand globally, new technologies and institutions will be required. This will be even more critical if the world moves to closure of the nuclear fuel cycle and the recycle of fuel materials.

The combination of challenges in both the technologies and in the institutions of the nuclear fuel cycle provides rationale for a long-term CAES role. With its own technical resources and that of the INL and its University partners, CAES is well positioned to contribute technology. With the Energy Policy Institute (EPI), CAES will contribute to key institutional issues such as the internationalization of nuclear fuel cycle activities.

Fuel cycle activities are multidisciplinary by nature. Engineering, physics, chemistry, mathematics, and simulation, for example, play key roles. This multidisciplinary approach increases the value of the CAES/INL/University consortia. Moreover, the IUC is building an ACE for fuel cycle activities.

An activity initiated by the INL in FY-05 is the SINEMA fuel cycle modeling and simulation research. This is at present an INL activity that will have increased CAES and university involvement. INL researchers will partner with CAES, IUC and NUC researchers in the development and use of what is envisioned to be a suite of modeling and simulation codes resulting ultimately in the world's most powerful and flexible fuel cycle simulation capability.

In FY-06, $\$ 150 \mathrm{~K}$ is anticipated to support the IUC development of a strategic plan for the nuclear fuel cycle research ACE. This will be leveraged with the institutional efforts of EPI to form a combined project, which will plan the CAES/IUC fuel cycle activity.

2. High Temperature Reactor Materials CAES will work with a sub-set (5) of the IUC and NUC universities to support and develop a proposal for a National Science Foundation (NSF). The Idaho Falls element of activities would be housed in the CAES facility. These activities will supplement those being developed through collocated centers and within INL programs.

3. Instrumentation \& Controls - Advanced NDE/Diagnostics Prognostics - CAES will facilitate an advanced NDE workshop focused on the needs of the Next Generation Nuclear Plant (NGNP) and Gen IV systems. The results of this workshop will help define a three-lab research effort (i.e. INL, ORNL, PNNL), with CAES coordinating.

\section{Non-nuclear Energy Research}

Discussions and activities were initiated during FY-05 and the process of identifying unique CAES non-nuclear research areas will be expanded during FY-06. CAES will conduct a series of workshops to further refine and develop appropriate research topics given its collective research capabilities (INL, IUC, NUC, etc.). Some initial areas being considered include:

1. Hydrogen - Scientific and engineering advancements must be made to realize the potential benefits of a hydrogen economy. In the long term, hydrogen will have to be produced without the release of carbon dioxide and by using abundant and reliable feedstocks. CAES will work with INL, university and industrial partners to help develop the hydrogen science and technology 
bases needed to secure our nations' energy future. Specific areas of research being evaluated include fuel reforming, e.g. coal, heavy diesel; electrolysis and thermochemical cycle development; biomass conversion; separations, purification and storage; and fuel cells.

\section{Carbon Management and $\mathbf{C O}_{2}$} Sequestration - Carbon dioxide emissions resulting from burning of fossil fuels play a key role in global climate change and continue to be a major international concern. CAES research, working with IUC, NUC and INL collaborators, may focus in the area of carbon capture, transformation and sequestration. Specific areas of research being evaluated include $\mathrm{CO}_{2}$ emissions modeling, transformation chemistry and subsurface storage technology.

3. Coal and Fossil Energy - Coal and fossil energy sources continues to play critical roles in the US and global energy supply. CAES will work with INL and industry research teams to help advance new science needed to improve the utilization and environmental acceptability of these resources. Areas of research will need to be more thoroughly defined but likely will involve improved conversion science and technology. Workshops will be conducted in FY-06 to better define and focus this area of research.

4. Energy and Water - Energy, water, and environmental sustainability are inextricably linked to U.S. economic performance as well as the health and welfare of our citizens and environmental quality. Maintaining abundant, sustainable sources of clean water is dependent on the availability of clean, inexpensive, and sustainable energy. Likewise, our nations' energy goals cannot be reached without simultaneously addressing the use of water for power plant cooling, emissions scrubbing, and energy production related issues. The magnitude of the challenge facing us to manage the nexus between energy and water is enormous since the projected needs of both energy and water are expected to grow substantially over the next 25 years.
CAES will work with the INL, IUC and NUC collaborators to establish and implement research to better understand the water cycle and water utilization, as they pertain to energy production and utilization. The science and technologies necessary to help optimize the use of our water resources and the production and utilization of energy also needs to be better understood.

\subsubsection{Energy Policy Institute Startup}

The Energy Policy Institute (EPI) will lead a comprehensive national, international, and regional dialogue on nuclear energy and other energy policy issues that span the range of topics including energy technology mix, energy-water nexus, consequences and impacts to the economy, society, natural resources, and the environment.

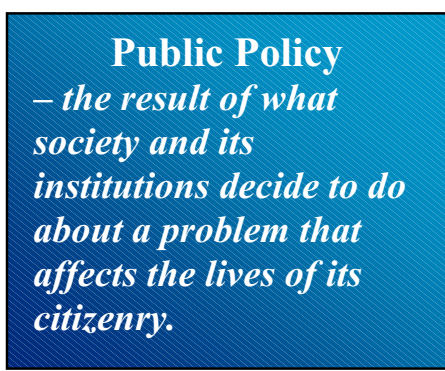

During FY-06 EPI will be establishing its organization through the hiring of key staff. An Interim CAES Associate Director for Energy Policy will be in place early in FY-06 and activities will be initiated in Idaho Falls. A national search will be performed in FY-06 to hire a permanent CAES Associate Director for Energy Policy. The selected individual is expected to also serve as a tenure track professor at BSU. Additionally, EPI staff, faculty and graduate assistants will be retained.

EPI will assemble a community of interested parties and will begin to execute its research agenda through strategic partnerships with other institutions, presenting research papers at national conferences, and conducting energy policy seminars and workshops. An initial policy study will be performed and reported in FY-06. During FY-07, EPI will showcase its capabilities by organizing and hosting an initial Energy Policy Conference. These activities are expected to build on the initial study to be performed in FY-06 and to form the basis for establishing the EPI 
distinctive signature, looking at the policytechnology interface.

The EPI will complete a business development plan that includes identification of potential funding opportunities. Proposals will be developed and submitted to targeted organizations in FY-06-07. Activities will be conducted to enable a fully functioning EPI to be prepared to move into the new CAES facility in Idaho Falls in FY-08 and for EPI to be supporting and aligned with activities at BSU.

\subsubsection{CAES Communications}

During FY-05, CAES began the implementation of various communication mechanisms. These efforts will continue to be expanded in FY-06 to generate further awareness and advocacy for CAES and its activities.

\section{Informational Outreach}

The Center informational outreach efforts will include the routine generation and distribution of various information packages. These information packages involve electronic, video and hardcopy media including text, brochures, newsletters, videos, web pages, photographs, drawings, graphics, and other materials as needed.

The CAES web site at http://CAESenergy.org will be further developed to become a key information portal. Periodic electronic newsletters will be distributed to interested individuals, organizations and the affiliate network.

\section{Technical Exchanges}

\section{Seminar Series}

The Center is working with the IUC and the INL to initiate the CAES Seminar Series during FY-06. Similarly, one result of the initial interaction with the Dalton Nuclear Institute leadership, late in FY-05, was mutual interest expressed in a joint seminar series. This seminar series will include the active participation of visiting scientists and engineers as well as key CAES-affiliated experts. Invited lectures will address a diverse set of energy related topics including nuclear energy, alternative energy sources, energy policy, economics, waste management, and nonproliferation. This series is expected to be open to the public.

\section{Workshops}

The Center is working with the IUC and the INL to define a series of CAES workshops. These workshops will be instrumental in formulating the technical agenda for CAES. For example, EPI will organize workshops and surveys of citizenry, policymakers and other interested stakeholders to help establish priorities of relevant energy policy issues.

\section{Conferences}

The Center representatives will be active participants in national and international conferences. This participation will serve to present the work conducted via CAES as well as to promote CAES and its affiliates. Participation will include presentation of individual technical work, programmatic overviews and conference/session coordination.

The Center is scheduled to participate, at a minimum, in the following annual conferences during FY-06.

- American Nuclear Society Winter Meeting, Washington D.C. - November 2005

- ISU Regional Energy Conference - November 2005

- Waste Management 2006, Tucson, AZ February 2006

- American Nuclear Society Summer Meeting, Reno, NV - June 2006

- American Society of Engineering Education Annual Conference - June 2006

- Alternative Energy Week, Boise, ID, September 2006.

The Center has also started planning efforts for an advanced NDE workshop, which will look at Very High Temperature Reactor and Generation IV needs.

Consideration is also being given to establishing a CAES Research Conference. This conference could be structured similar to the "Review of Progress in QNDE", that is run by the 
Iowa State University, NDE Center, and the "XRay Conference" coordinated by the Physics Department of the University of Denver. Such a conference would have published conference proceedings and could become a focus for national activity in selected technical areas that support advanced nuclear energy.

\subsubsection{Infrastructure Development}

A partnership between the State of Idaho, the IUC, and BEA will complete construction of the CAES facility at University Place in Idaho Falls in 2008. This new CAES facility will enable the collaboration of university, CAES administration, INL researchers, and other affiliate members.

The CAES facility will be a premier international user-facility for promoting, performing research and revitalizing education and training in nuclear energy science, engineering, technology, and related disciplines (see Figure 5). The facility is expected to encompass 50$60,000 \mathrm{ft}^{2}$ with approximately $50 \%$ of the facility will be dedicated to laboratory space and will be opened during 2008. The facility is envisioned to be a two-story, structural steel building with a brick façade. Coordination with other University Place and INL planned building initiatives will ensure the architecture is compatible with the overall campus design.

With CAES and the collocated centers, including industry partners, it is anticipated that this facility will house, when fully occupied, a total of 175 people including approximately 100 faculty, researchers and staff, 50 graduate students and 25 undergraduate students from the 2+2 Program.

\section{CAES Infrastructure Development Project}

The IUC and CAES are working together to meet the requirements of the State Board of Education. The building will be a university building located on state/university land. The CAES infrastructure development project team is lead by an ISU Project Manager. Core project team members include an engineering manager (ISU), a project controls lead (ISU), a construction lead, a finance lead (ISU), an INL representative (to coordinate all INL inputs to design), a UI representative, a BSU representative, and a project architect from the Idaho Division of Public Works. This group is working in close cooperation with the CAES Steering Committee and State Board of Education for final approvals.

The current planning assumption is that this new building will be located at the ISU/UI Center for Higher Education at University Place in Idaho Falls. A final siting decision is expected to be made during the first quarter of FY-06. CAES and the IUC have held building requirements workshops and an outline requirements document is ready for transmission to an architectural firm. IUC and the Idaho Division of Public Works will issue a request for proposal and award a contract to an architectural engineering firm to complete the design and then subcontract for the construction based on the completed design.

\section{Bonding/Guarantees}

The design and construction of the Stateowned CAES facility is estimated to cost approximately $\$ 14$ million. 


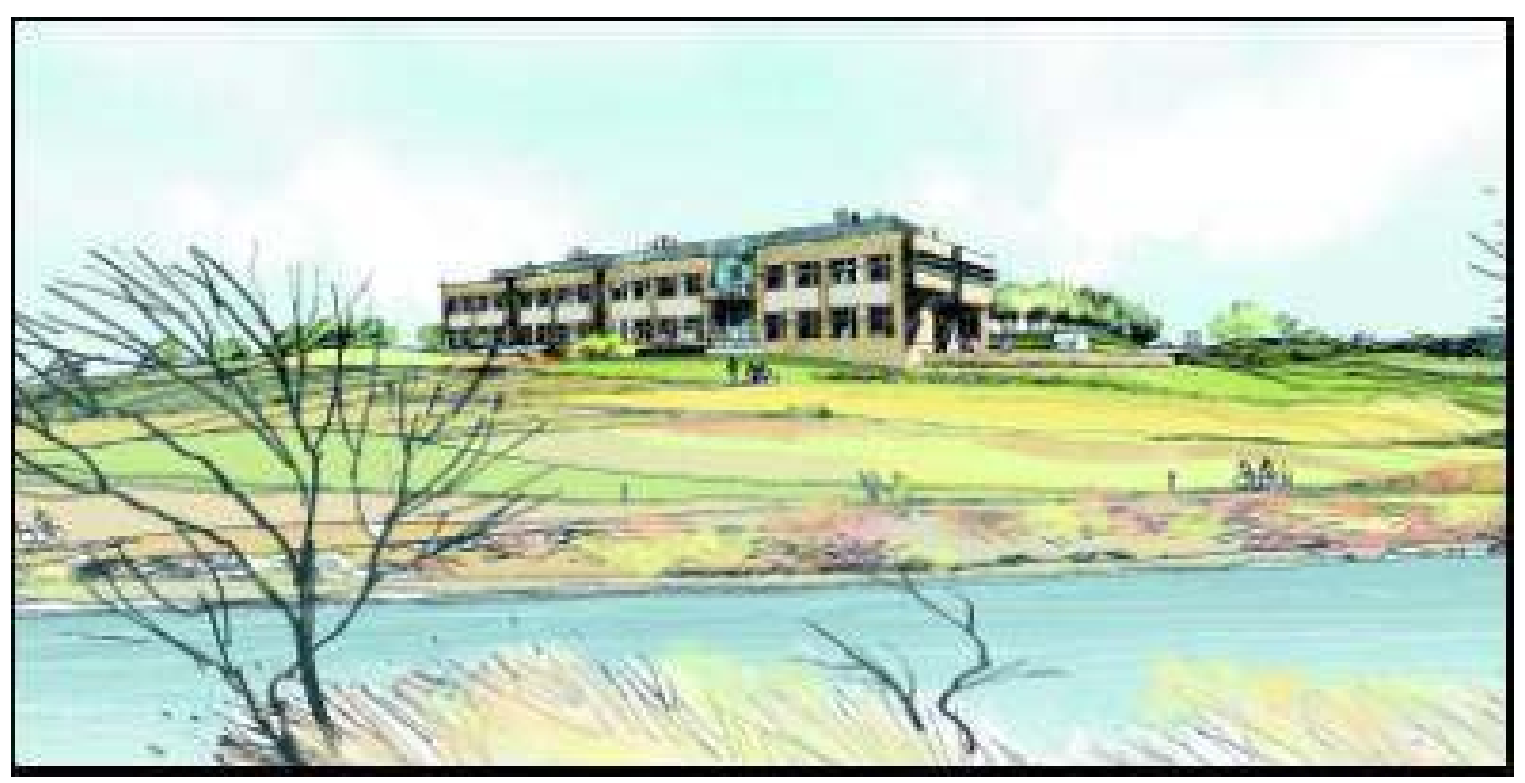

Figure 5. Conceptual Illustration of the Future CAES Facility.

Funding for this facility has been obtained as follows:

- A total of \$5 million dollars from the INEEL Settlement Fund, as defined in the Idaho Code 67-806A, for use according to the terms of the agreement for the construction of the Center for Science and Technology in Idaho Falls, dated June 29, 2001, between the Office of the Governor of the State of Idaho and the Regents of the University of Idaho and the Trustees of Idaho State University.

- A total of $\$ 1,942,756$ in grants from the U.S. Department of Housing and Urban Development (HUD) to the University of Idaho, HUD Grant B-00-SP-ID-0116 in the amount of $\$ 925,000$ and HUD Grant B-01-SPID-0172 in the amount of $\$ 1,017,756$ for use according to the terms of the grants.

- Additional support for the design and construction of the CAES through the issuance of bonds, exempt from federal income taxation in the amount of an additional $\$ 7$ million by Idaho State University to be retired over 20 years, by rent paid by BEA and its affiliates for occupancy of approximately $50 \%$ of the CAES facility.
The CAES building will be constructed following all laws and regulations of the State of Idaho and the project will be administered under the provisions of Idaho Statutes of Title 67, Chapter 57. The Idaho Division of Public Works will secure all plans and specifications for, let all contracts for, and have charge of and supervision of the construction of the CAES facility.

\section{Equipment Acquisition}

The normal "supplied with construction" equipment (such as HVAC and laboratory fixtures) will be included in the allocated CAES facility development funding and will be supplied under the construction subcontract. Specialty equipment and equipment to be installed after the building is completed, to support the CAES program, education, research, and the collocated Centers is provided by other sources.

Specialty equipment for the new CAES facility will be provided through a combination of sources including: (a) INL excess equipment, (b) direct programmatic funding, (c) university funds, and (d) large items, through INL and university capital equipment and DOE funds. 


\subsubsection{Operation, Management and Performance}

The Formulation Phase of CAES - Phase 1 is intended to establish the foundation on which CAES will build a world-class entity. This foundation includes the establishment of key partnerships and the development of necessary infrastructure, and the formulation of researcherfriendly administrative tools.

During Phase 1 CAES will initiate an annual CAES meeting, which will include presentations and discussions of key projects, programs and business development activities. CAES will also initiate its semi-annual Executive Advisory Committee Meetings and strategic planning workshops.

The operation, management and performance monitoring mechanisms will be developed and implemented to ensure successful execution of this program plan. Prior to the establishment of CAES as an independent entity CAES will operate in accordance with INL and BEA practices and requirements. A CAES handbook will be developed during Phase 1 to aid collaborators, researchers and staff for the transition to an independent entity.

The Center will identify and apply operating policies from other related and successful institutions such as the National Science Foundation (NSF) Industry/University Cooperative Research Centers Program (Gray and Walters, 1998), other Battelle-operated National Laboratories (Oak Ridge National Laboratory, Pacific Northwest National Laboratory), and the National Space Science Technology Center (NSSTC). For example, NSSTC, a partnership between National Aeronautics and Space Administration (NASA) Marshall, seven Alabama research universities and the State of Alabama, has a 20-year history and currently has 350 to 400 people actively engaged in its research efforts. This successful organization, described as a "confederation", has received strong State, university and NASA support.

A survey of energy research centers was performed by BSU and INL staff and has been reported to CAES (O'Brien and Louis, 2005).
CAES leadership will continue to learn from both successful, and less successful centers and policy organizations.

A set of CAES performance metrics will be developed during Phase 1 . These metrics are expected to include:

- The number of Peer Reviewed Publications (and Citations/Impact)

- The number of Conference Presentations

- The number of issued Reports

- Business Volume

- Collaborative Partnerships

- The number of Staff, Affiliate and Associated Faculty and Students.

A summary of activities and performance against these metrics, including interactions with collocated and collaborating centers and the university network will be provided in the Annual Report and presented at the Annual meeting. Other periodic reports and information will be provided through semi-annual newsletters and the CAES web site (http://CAESenergy.org).

\subsection{Phase 2 - CAES Implementation (2008-2010)}

The Center Implementation - Phase 2 will focus on development of a full spectrum of programmatic activities in education, research, training and policy studies while operating as an independent nonprofit entity, and expanding its collaborations as the hub for the university network. These activities will be key to supporting the INL transformation, including the revitalization of the human capital (workforce), workforce skill-mix adjustment, engagement of the wider research community, workforce pipeline development and support of the INL workforce diversity strategic hiring goals and objectives.

The Center will be functioning as the hub for a university network and a network of wider collaborations, both in the United States as well as internationally and will serve as a gateway for contacts with INL researches and facilities. 


\subsubsection{Occupy New CAES Facility}

The commencement of Phase 2 is scheduled to coincide with the completion of the new CAES facility. This facility will serve both as a visible achievement as well as be a key physical enabler for CAES to progress towards its programmatic vision.

The Center administrative and research staff, INL researchers through the collocated research centers and institutes, and CAES affiliate faculty and researchers will jointly relocate into the new CAES facility during FY-08. The collocation of government, academia and private industry resources and staff will foster CAES interactions and technical collaborations.

It is expected that the building will be at least $50 \%$ occupied by the end of FY-08 and the full occupancy of 175 people will be achieved by 2010.

\subsubsection{Transition to Nonprofit Entity}

During Phase 2 CAES will move to be organized and recognized as an independent nonprofit entity. It is anticipated that CAES will transition to a nonprofit entity by FY-10 (accelerated schedule is during 2008). This transition will move CAES from its current internal INL organizational status, operating with an MOA that establishes the teaming with three Idaho universities and an expanded affiliated university network (the 5 charter members of NUC), to an independent entity. This nonprofit transition will better position CAES to begin operating consistent with IRS requirements including the establishment of complete and independent records (establishment of 24-month operating history) that will be used in support of tax-exempt status consideration. Initial review of requirements and planning for this transition began in FY-05. The detailed planning for this transition approach will be completed in FY-06.

\subsubsection{Program Achievements}

The Center programmatic achievements will continue to be realized during this Implementation Phase. These accomplishments will be evident in each of the CAES technical areas.

\section{Research}

It is expected that CAES will focus its research efforts in 3-5 critical areas, which align with its distinctive expertise. These research signatures will form the basis for CAES research activities, business development and delivery on grants and contracts. In each area it will be necessary to achieve and maintain a critical mass for the research effort (expected to be \$3-5M per area). Performance will be measured using the CAES performance metrics and reported at the annual meeting and through the Annual Report.

\section{Education}

A CAES education committee, established in Phase 1, will ensure that needed courses are provided through the IUC. A core activity will continue to be to support the " $2+2$ " B.S. in Nuclear Engineering and to enable it to be an accredited program with internships at the INL site. At least 50 graduate students and post-docs will be associated with CAES activities.

In addition to graduate and undergraduate education the CAES Seminar Series will have been established and will be attracting national and international lecturers. Additionally, a program of short courses, and workshops will be fully functional.

Following on the success of the first WNU, Summer Institute 2005, CAES will seek to maintain and develop its interactions with the WNU and host a second WNU Summer Institute that is provisionally planned for 2007 or 2008 .

\section{Policy}

The CAES EPI will be fully established before the start of Phase 2. As such, EPI will be performing an expanded number of policy studies, hosting workshops and increasing its impact as a center for thought leadership.

EPI will be establishing a recognized and distinctive signature, currently anticipated to be the technology-policy interface. It will work closely with the INL to integrate with the INL energy security strategy (Figure 6). 


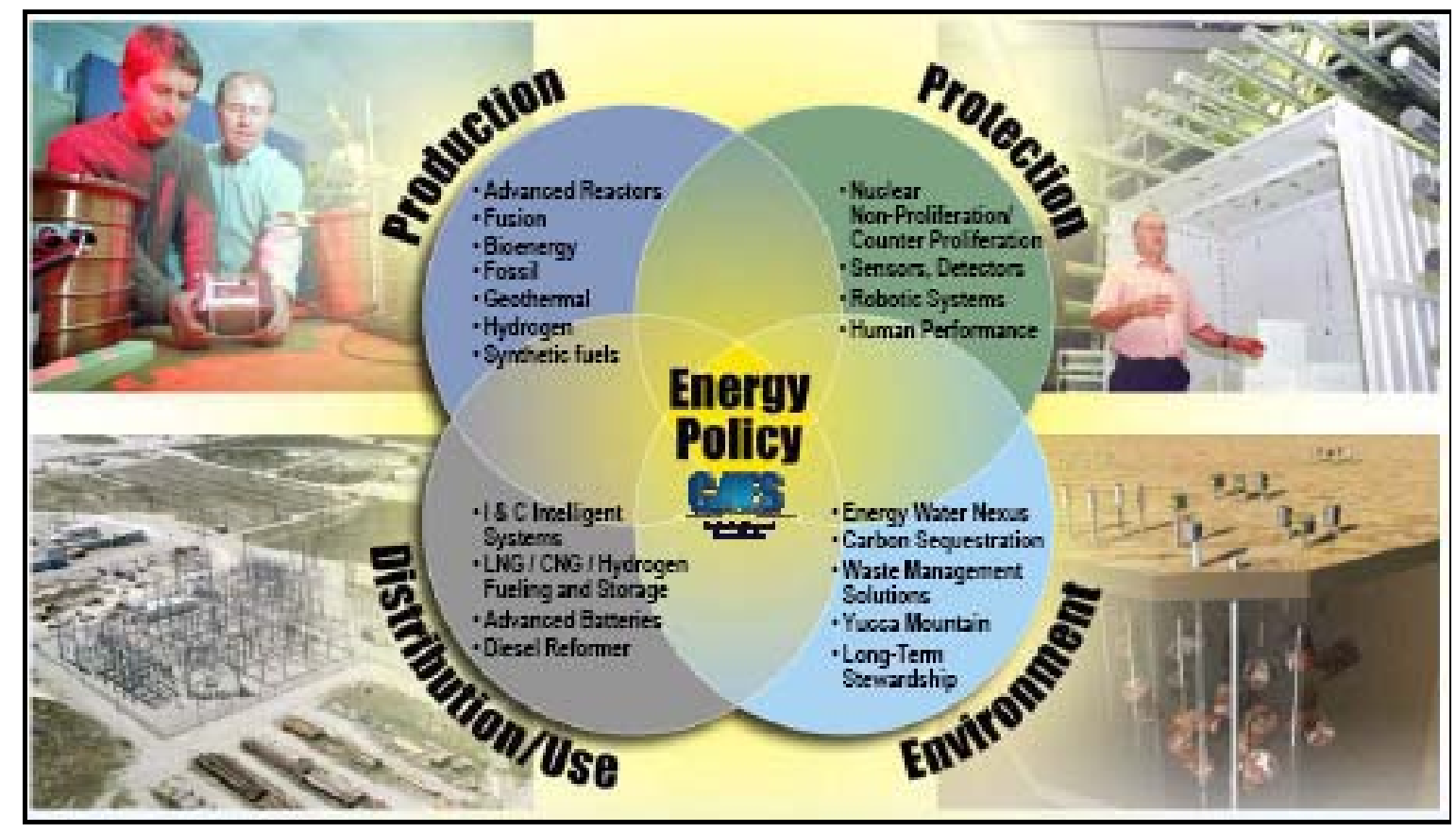

Figure 6. INL's Energy Security Integration.

EPI will have an expanded set of partnerships with such groups as the Joint Global Change Research Institute and the Global Energy Technology Strategy Program.

\section{Training}

The Center will be integral to the training efforts in the energy community. As an implementation resource to EPRI, INPO and NEI, CAES will help train and develop the nuclear workforce at the crafts/technician level. By providing leadership, support and coordination, CAES will help strengthen national energy-related curricula presented at community colleges, vocational technical schools and tribal education institutes nationwide.

A full-cost recovery Startup Engineering Training and Resource Program will provide training and information resources for reactor startup activities to national and international clients. This program will be staffed with both permanent and as needed technical personnel from industry and the NRC.

The Center will serve as a national and international training resource. In cooperation with the INL Technical Library CAES and INL will hold the largest standing resource base of reactor startup literature and information resources in the world. As an international resource CAES will support the International Atomic Energy Agency (IAEA) in addressing the questions of workforce development and knowledge capture.

\subsection{Phase 3 - CAES Operations (2010-2015+)}

\subsubsection{Sustainable Operations}

As an independent entity, CAES must achieve a self-sustaining funding stream based on its technical and programmatic contributions. CAES revenue streams include direct programmatic funding, funding obtained by the researchers and EPI, the four affiliated independent centers, sublease payments from affiliate members, as well as financial support from both the DOE and the INL. It is intended that CAES operate as an independent organization no later than the beginning of FY-12. The long-term operating position for CAES is that CAES revenue will be $1 / 3$ DOE, $1 / 3$ other federal agencies and $1 / 3$ other 
grants and contracts, including payments for space and collaborating activities and provision of administrative services to collocated centers and related industrial partners.

The personnel costs associated with CAES researchers, staff, students and affiliate members dominate CAES costs. A CAES business model is presented in Section 7. This model projects a positive net cash flow for CAES that will enable investment and growth. Achieving this vision is dependent on adequate investments being made in CAES activities in both Phase 1 and Phase 2.

\subsubsection{Programmatic Accomplishments}

\section{Research}

The CAES distinctive research signatures will have been used to integrate faculty, students and researcher activities. These research signatures will continue to form the basis for CAES research activities, business development and delivery on grants and contracts. In each area it will be necessary to achieve and maintain a critical mass for the research effort (expected to be $\$ 3-5 \mathrm{M}$ per area). Performance will be measured using the CAES performance metrics and reported at the annual meeting and through the Annual Report.

\section{Education}

Nuclear engineering and science research will be growing nationwide. The educational opportunities provided by the Idaho universities in partnership with INL and CAES will be seen as a key component of this revitalization. A collaborative bridge between Idaho, national and international universities and the INL will have been established and will be fully functional.
Graduate and undergraduate students will be receiving practical work experience through this broad educational network. Distance learning capabilities will support enhanced student-facultyprofessional interactions. Access to government, industry and university resources will provide unique, one-of-a-kind educational opportunities.

\section{Policy}

The CAES EPI will be fully established and operational. EPI will continue to perform an increasing number of significant policy studies and workshops. Through these efforts EPI will be recognized internationally as a pre-eminent energy policy institute.

Through its broad collaborative partnerships EPI will come to be instrumental in identifying energy-related issues and formulating solutionoriented energy policy.

\section{Training}

The Center will be identified as a leader for the development of training curriculum, activities, and materials for future generation reactors. The establishment of technical training programs in support of the nuclear industry will gain international recognition for CAES. CAES will also be an advisor to the Nuclear Regulatory Commission for training and workforce-related questions.

\subsection{Program Schedule}

The following Program Schedule details the activities, milestones and key deliverables for CAES for the period FY-06-10. 


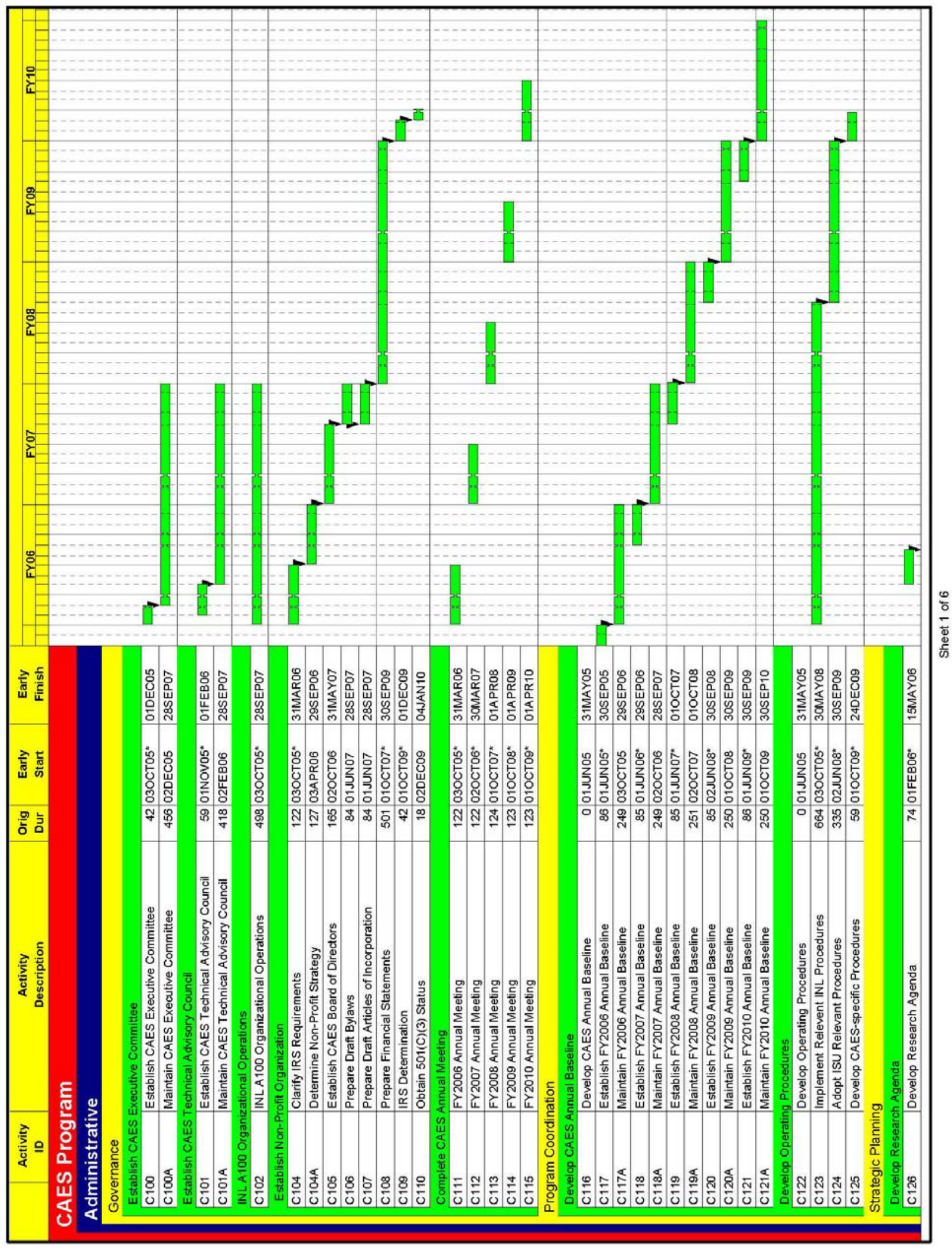




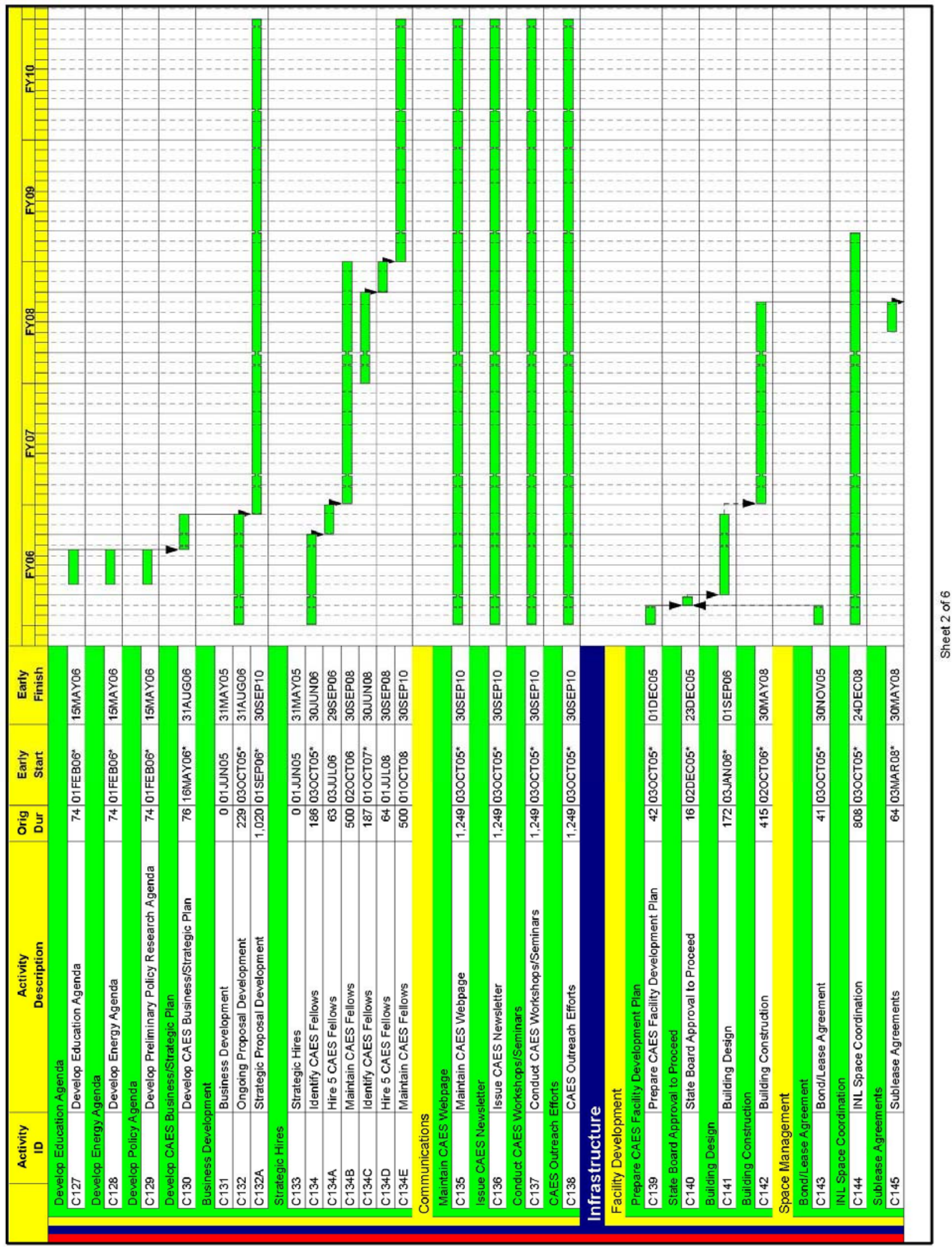




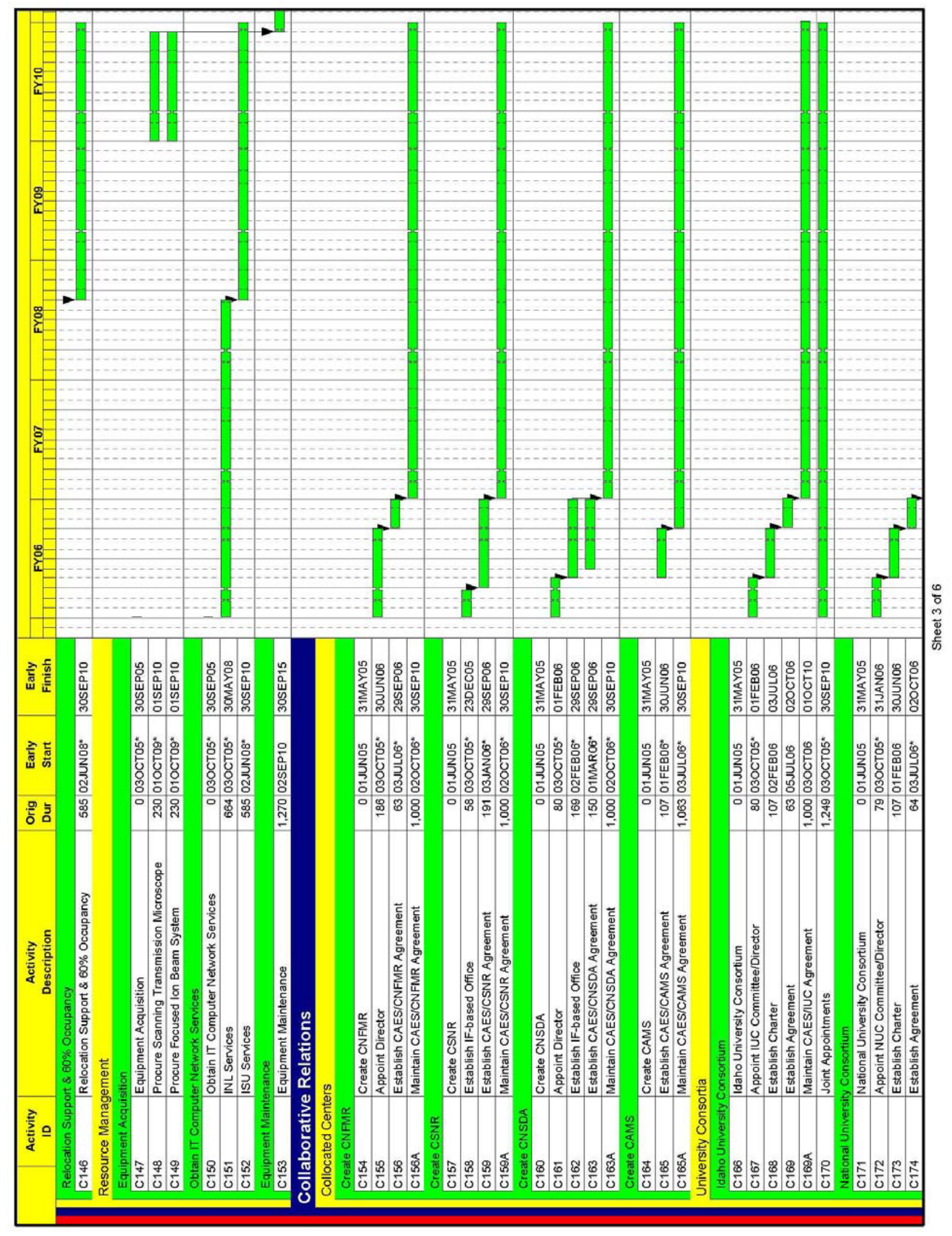



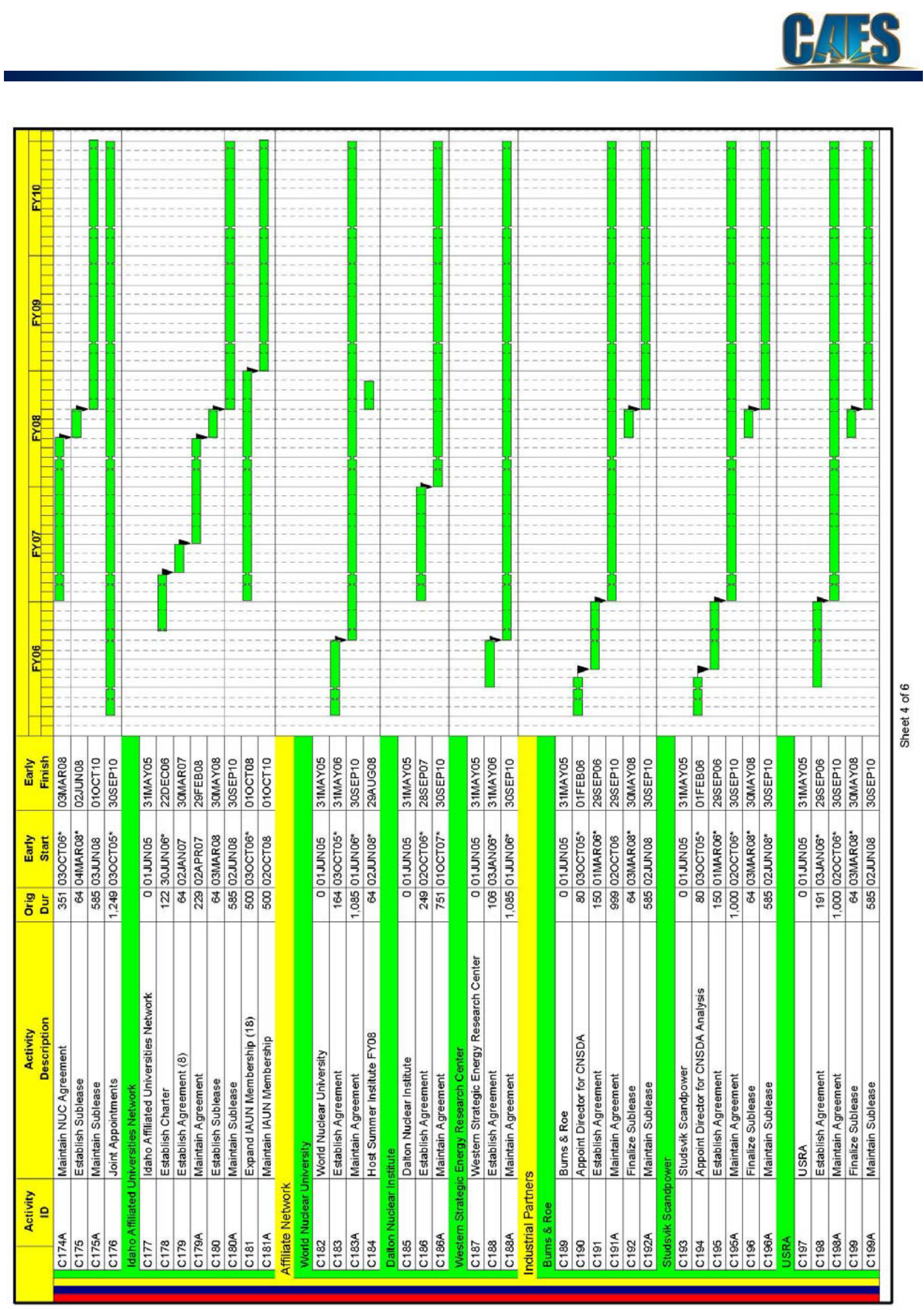


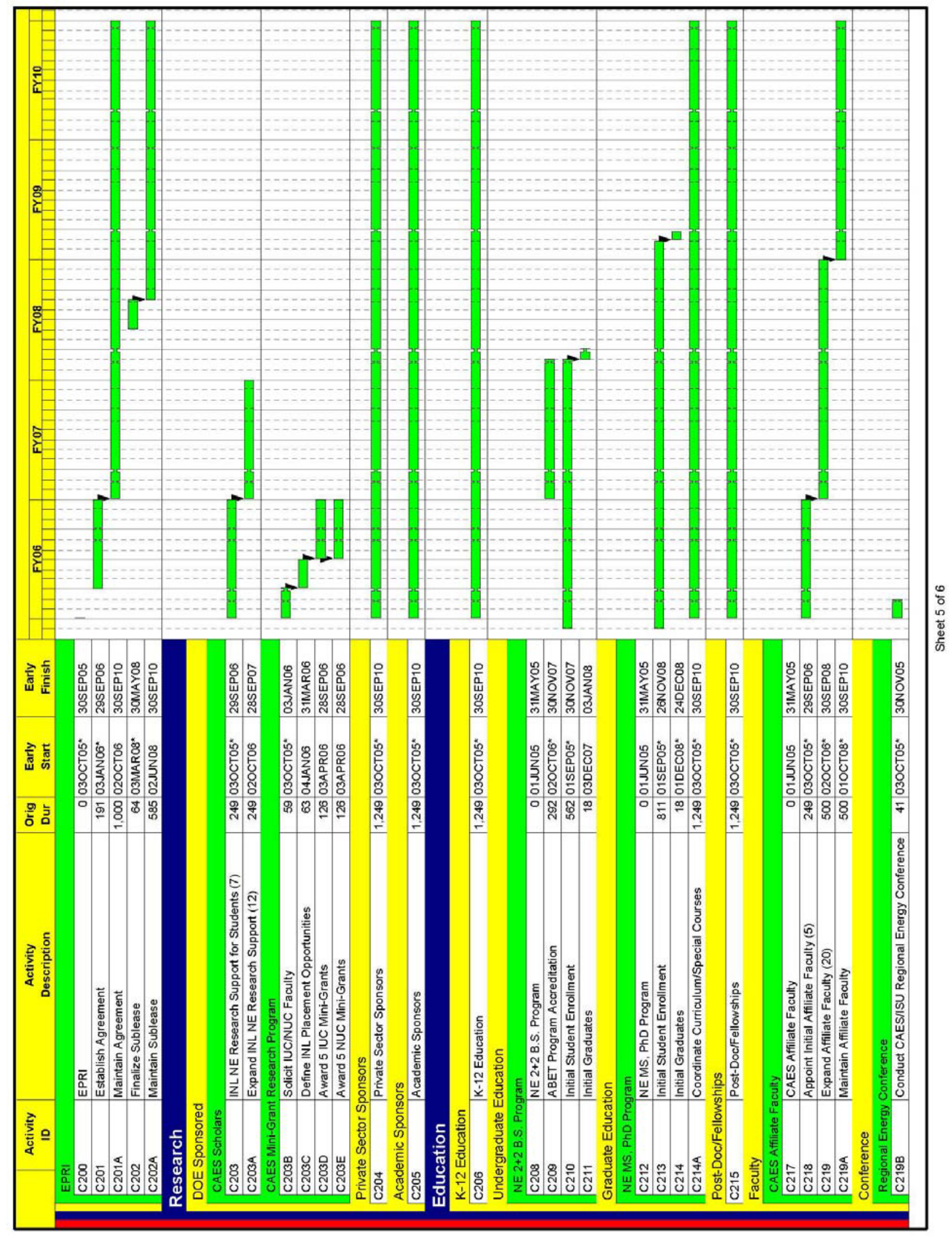



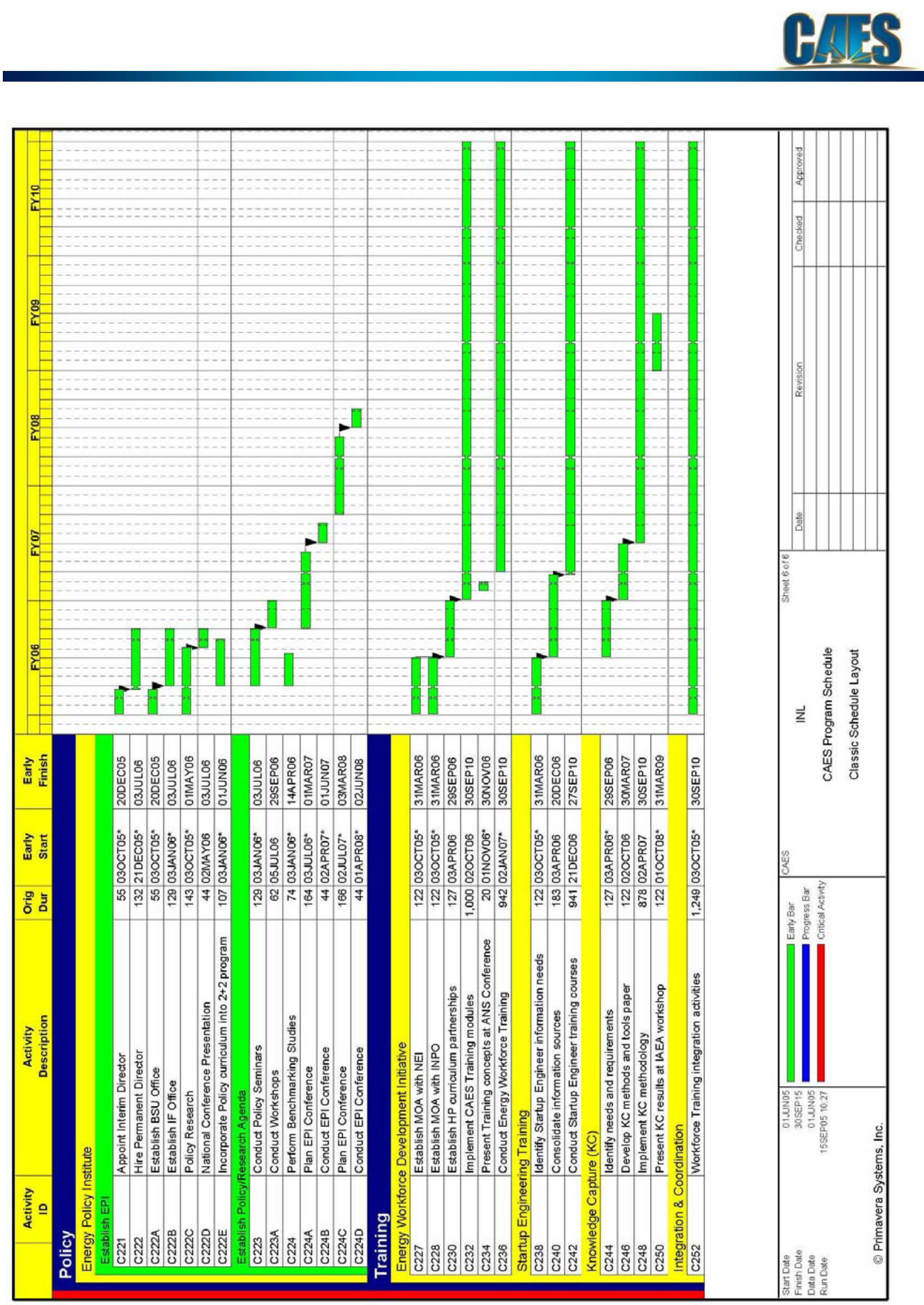
B.

28

28 


\section{ORGANIZATIONAL STRUCTURE}

The organizational structure of CAES is initially that of an internal organization (Org. A100) within the INL with the CAES Director reporting directly to the INL Laboratory Director. This initial CAES organization is designed to facilitate start-up operations of CAES including establishment of the administrative organization, the formulation of collaborative relationships, the establishment of research, educational, policy and training agendas and cooperation with universityled infrastructure development efforts.

Figure 7 illustrates the current CAES organization. The roles and responsibilities of the various CAES members are discussed in the following sections.

\subsection{Steering Committee}

The CAES Steering Committee, established in FY-05, provides oversight for the Formulation Phase of CAES program (Phase 1) and for facility development. The membership of this committee includes:

- INL Chief Research Officer (Chair, Dr. Bill Rogers)

- Director, CAES (Dr. Leonard J. Bond)

- Vice-President for Academic Affairs, Idaho State University (Dr. Robert Wharton)

- Vice-President for Research, University of Idaho (Dr. Charles Hatch)

- Interim Vice-President for Research, Boise State University (Dr. Jack Pelton).

Under the leadership of the Steering Committee, CAES, in partnership with the State, IUC member universities, and INL staff will develop detailed program and project plans including business development activities.

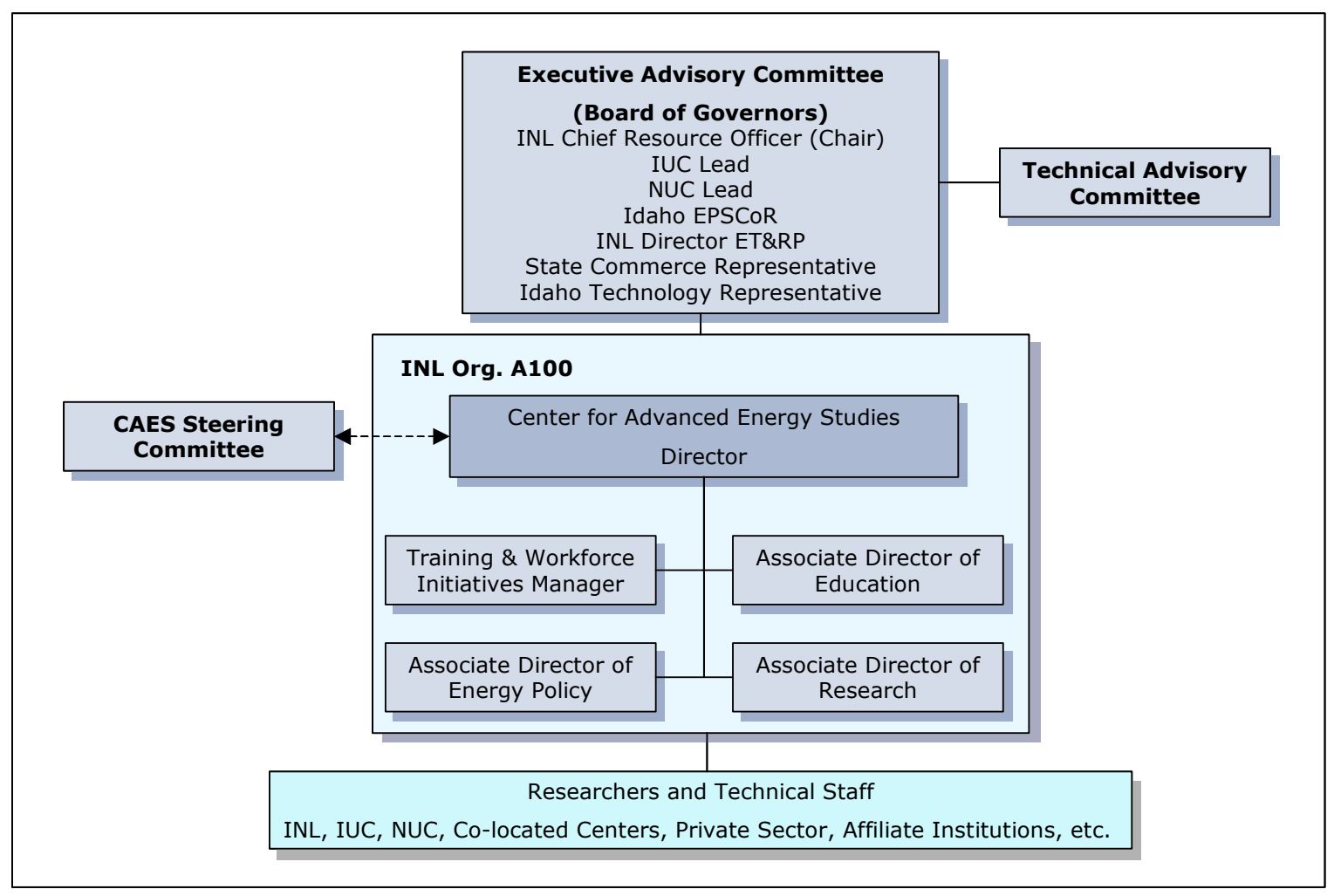

Figure 7. CAES Organizational Chart. 


\subsection{Executive Advisory Committee (Board of Governors)}

A CAES Executive Advisory Committee, to be established during FY-06, will be responsible for oversight of CAES policy, budgeting, planning, human resources, and program evaluation. This Committee will serve initially as an Executive Advisory Committee until such time as CAES moves to a nonprofit status at which time it will be formalized as the Board of Governors.

The initial membership of the CAES Executive Advisory Committee (Board of Governors) is anticipated to include:

- INL Chief Research Officer

- Idaho University Consortium Representative

- National University Consortium Representative

- Idaho Experimental Program to Stimulate Competitive Research (EPSCoR) Representative

- INL Director of Education, Training, and Research Partnerships

- State of Idaho Commerce Representative

- State of Idaho Technology Representative

- State Board of Education Representative.

\subsection{Technical Advisory Committee}

The CAES Executive Advisory Committee (Board of Governors) will establish, during FY06, a Technical Advisory Committee consisting of 5-8 members. This advisory committee will be formed as a subcommittee of the Executive Advisory Committee and will support CAES by providing technical guidance and recommendations. These recommendations will primarily focus on enhancing the CAES programs in research, education, policy and training.

\subsection{CAES Administration and Staff}

The CAES administration organization is responsible for all operational aspects of CAES. As an INL organization, CAES position descriptions, qualifications, and experience requirements are being developed in accordance with the current INL job classification requirements. Formal R2A2's (roles, responsibilities, accountabilities and authorities) will be developed for each CAES position. These R2A2's will be used to guide CAES members and will establish performance expectations. All senior staff will be expected to actively engage in both research and educational activities of CAES.

Each CAES Associate Director and Manager will have programmatic and related responsibilities in the areas of (a) Research,

(b) Education, (c) Policy Studies, and

(d) Training, respectively as well as crosscutting collaborative roles.

\subsubsection{Director}

The CAES Director, Dr. Leonard J. Bond, serves as the program lead for CAES operations. Responsibilities of the Director include all aspects of program formulation, implementation and operation such as safety, quality and technical excellence. Operational activities include, but are not limited to, the management of human, capital and financial resources.

\subsubsection{Associate Director for Research}

The CAES Associate Director for Research will serve as the program lead for CAES research. Responsibilities of the Associate Director include business development and coordination of all CAES sponsored and affiliated research. Activities include establishment of collaborative agreements, development of joint research proposals, coordination of research operations, and management of product delivery in terms of quality, schedule, costs and technical excellence. This position is anticipated to be filled during 
the first quarter of FY-06. This position is anticipated to be a joint appointment with the UI.

\subsubsection{Associate Director for Education}

The CAES Associate Director for Education, Dr. Michael Lineberry, serves as the program lead for CAES educational programs. Responsibilities of the Associate Director include coordination of all CAES sponsored and affiliated educational programs. Activities include establishment of collaborative agreements, development of joint educational proposals, coordination of educational programs, development of workshops, short courses, seminars and management of product delivery in terms of quality, schedule, costs and technical excellence.

\subsubsection{Associate Director for Energy Policy}

The CAES Associate Director for Energy Policy will serve as the program lead for CAES energy policy programs. Responsibilities of the Associate Director include coordination of all CAES sponsored and affiliated policy research. Activities include establishment of collaborative agreements, development of joint policy proposals, coordination of policy programs, and management of product delivery in terms of quality, schedule, costs and technical excellence. This position will be filled with an Interim Director during the first quarter of FY-06. It is expected that this position will be permanently filled following a national search and that it will be a joint appointment with the BSU.

\subsubsection{Manager of Training and Workforce Initiatives}

Mr. Richard Holman currently serves as the Acting CAES Manager of Training and Workforce Initiatives. In this capacity, Mr. Holman, serves as the acting program lead for CAES Training and Workforce Initiatives. Responsibilities of the Manager include coordination of all CAES sponsored and affiliated training and development programs. Activities include identification and establishment of collaborative agreements, development of joint workforce program proposals, inter-organizational coordination of workforce development programs, program coordination with other energy sector professional and trade organizations, and management of product delivery in terms of quality, schedule, costs and technical excellence. In FY-06 the requirements for this position will be reviewed and it will be determined if this should be established as a CAES Associate Director or Manager position. It is anticipated that this position will be permanently filled during FY-06, as funds become available.

\subsubsection{CAES Researchers \& Technical Staff}

The Center researchers and technical staff will initially be obtained from its affiliate organizations. This will include faculty and students from IUC, NUC and other affiliate universities. Additionally, CAES researchers will also include affiliate scientists from National Laboratories and private industry. These researchers and staff will engage in collaborative projects and joint proposals. Faculty and INL researchers will be appointed, as appropriate to CAES affiliate positions.

To facilitate this collaborative environment, CAES is in the process of establishing the mechanisms to obtain Joint Appointments between CAES and its affiliate organizations. The legal framework necessary to achieve these appointments is currently under development and review.

\subsection{Energy Policy Institute}

The Energy Policy Institute (EPI) will lead a comprehensive national, international, and regional dialogue on nuclear energy and other energy policy issues that span the range of topics encountered in consideration of the energy future of the nation, including consequences and impacts to the economy, society, natural resources, and the environment.

Operating as a distributed institute within CAES and with offices located in Idaho Falls 
and Boise, EPI will assemble a community of interested parties. By utilizing the latest collaborative problem-solving and decisionmaking methods and tools, EPI will map the values and trade-offs involved in defining and solving the nation's energy-related problems. The output of these discussions along with the research conducted under EPI's guidance will provide policy-makers, citizens, and other interested parties with relevant and timely information to guide the development of energy policy.

The Energy Policy Institute will also be involved in educating and preparing tomorrow's leaders in the importance and application of energy policy in determining the nation's future energy mix. Students participating in the Institute's research and seminars will gain a reallife appreciation of the role that political decision-making has in energy-policy as well as the fundamental principles involved.

\subsection{Collocated Centers}

Four independent INL research Centers will be collocated within the new CAES facility. The collocation of these Centers is intended to foster technical collaboration. These Centers will establish collaboration agreements (in the form of MOU/MOA's), lease arrangements for space and support services. Some collocation will be started in FY-06.

\subsubsection{Center for Space Nuclear Research (CSNR)}

The INL is teaming with the Universities Space Research Association (USRA), University of New Mexico (Institute for Space and Nuclear Power Studies), and General Atomics to establish a Center for Space Nuclear Research (CSNR). CSNR will support the space nuclear research and educational mission needs of the United States and will reinvigorate research and education in space nuclear engineering within U.S. universities.

The CSNR will be an independent entity acting under the authority of the USRA, a nonprofit organization. The CSNR will develop, through its contacts with NASA and other government agencies, an independently funded research program that includes participation of INL scientists and engineers and university faculty and students. A Director, appointed by USRA, under contract with the BEA, will manage the CSNR. The CSNR will move to the new CAES facility as soon as possible.

\subsubsection{Center for Advanced Modeling and Simulation (CAMS)}

The Center for Advanced Modeling and Simulation (CAMS) is a Center established at the INL to provide advanced modeling and simulation/high performance computing for the Laboratory and other clients. CAMS will focus on four modeling and simulation areas that are important to advanced energy systems: (a) threedimensional transport modeling (radiation, heat, multiphase fluids), (b) behavior of both solid and fluid materials (based on computational material science) in extreme conditions, (c) design and layout of instrumentation and control systems (such as reactor control rooms of the future), and (d) implementation of the appropriate computing infrastructure, both hardware and software (see Figure 8). The CAMS will move to the new CAES facility as soon as possible and opportunities will be sought to develop joint modeling activities.

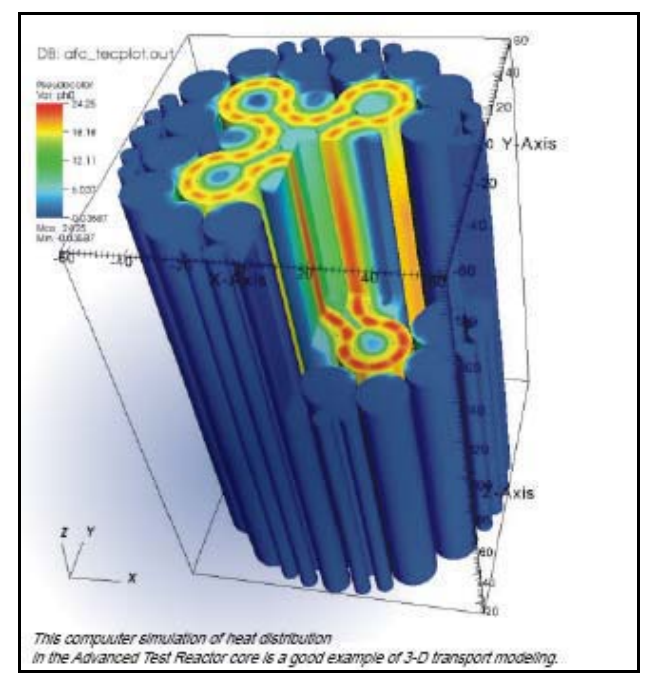

Figure 8. A 3-Dimensional Simulation of Heat Distribution in ATR. 


\subsubsection{Center for Nuclear Fuels and Materials Research (CNFMR)}

The Center for Nuclear Fuels and Materials Research (CNFMR) is a Center established at the INL to provide complete nuclear fuel and core materials evaluation capabilities in support of industry and government programs (see Figure 9). CNFMR works in collaboration with government, university and industry partners to develop, test and qualify new fuels and core materials for emerging operating requirements and for new reactor concepts; develop, evaluate, and qualify fabrication processes; and provide access to state-of-the-art facilities and equipment for clients to obtain fuels and materials research data. Opportunities will be sought to develop joint and related activities with the IUC and NUC universities that are seeking to develop sponsored activities in the area of high temperature reactor materials.

The CNFMR will establish an office in the new CAES facility as soon as possible.

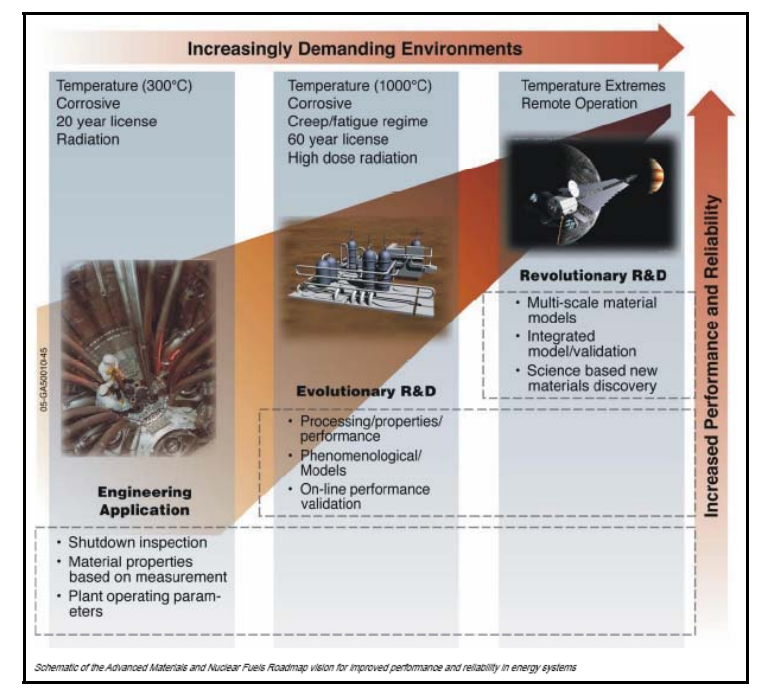

Figure 9. Illustrative Roadmap for Advanced Materials and Nuclear Fuels.

\subsubsection{Center for Nuclear System Design and Analysis (CNSDA)}

The Center for Nuclear Systems Design and Analysis (CNSDA) will be established to build understanding and acceptance of advanced nuclear plant designs and technology, support the training of the next generation of nuclear component and plant designers, develop the advanced design tools necessary to take advantage of the modeling and visualization technology available, and help create design basis criteria for future plants that are economically and efficiently achievable.

The CNSDA will be established in cooperation with industry. Burns and Roe Enterprises, Inc. a well-known architecturalengineering firm, and Studsvik Scandpower, a world leader in computational reactor physics, will be key partners in the establishment of the CNSDA. Burns and Roe will provide a Director to manage the CNSDA who will report to INL's Associate Laboratory Director for Nuclear Programs. Studsvik Scandpower will provide a Director to manage the analysis component of the CNSDA operations. The CNSDA, and staff from supporting industry partners, will move to the new CAES facility as soon as possible and opportunities will be sought to develop joint and related modeling activities.

\subsection{Idaho National Laboratory}

The Center is recognized as a major development enterprise of the INL and is central to its transformation (development of the INL University Network; INL human capital development, skill-mix realignment, re-tooling and revitalization and workforce diversification). As such, CAES draws upon the expertise of the entire INL organization. The advantage of this approach is that the existing organizational infrastructure can be utilized so as to accelerate the implementation of the CAES vision. This approach includes INL financial support for administrative and start-up costs, business development funds for collaborative proposal development, and technical support in terms of expert personnel.

The roles of several of the INL organizations involved in the establishment and implementation of CAES are discussed in the following sections. 


\subsubsection{INL Educational Programs}

The INL Education, Training, and Research Partnerships Educational Programs (ETRP) administer education contracts with Idaho, regional, and national colleges and universities that are aimed at promoting continuing education for INL employees. Through various programs, such as the INL Academic Center of Excellence, Inc., university faculty and students, industry professionals, and pre-college teachers are also connected with INL researchers and facilities.

The INL educational programs currently bring a growing number of students pursuing science, engineering, math, and technological degrees, at colleges and universities throughout the nation into the INL. CAES and its affiliate organizations will similarly be involved in a range of educational efforts. Appropriate educational efforts will be closely coordinated between ETRP and CAES to support both educational missions. During FY-06 a MOA will be established that defines CAES and ETRP roles and responsibilities.

\subsubsection{Nuclear Programs}

The mission of the INL Nuclear Programs organization is to develop advanced nuclear technologies that provide clean, abundant, affordable and reliable energy to the United States and the world. These efforts support the U.S. government's role in leading the revitalization of the nation's nuclear power industry and re-establishing U.S. world leadership in nuclear science and technology.

The INL maintains a full spectrum of research, development, and testing efforts in areas as diverse as nuclear power systems, lowenergy nuclear physics, system safety analysis, advanced fuel cycle processes, neutron capture therapy, and future technologies such as the next generation reactor technology.

\subsubsection{Nuclear Operations}

The INL Nuclear Operations organization maintains the nuclear infrastructure and operational expertise of the laboratory. Infrastructure capabilities include fuel manufacturing, conditioning and examination facilities; spent fuel handling and storage facilities; the Advanced Test Reactor; the Neutron Radiography Reactor; and post irradiation examination facilities.

\subsubsection{National Security}

The INL's National and Homeland Security Programs play a leading role in our nation's nonproliferation efforts. These efforts support the U.S. government's objective of reducing international threats associated with nuclear materials and weapons of mass destruction.

The Center will obtain the national security, nonproliferation and safeguards \& security expertise from the INL, which maintains a range of research, development and testing capabilities. These capabilities include development, prototyping and testing capabilities as well as risk and vulnerability assessment capabilities.

\subsubsection{Science and Technology}

The INL conducts fundamental and applied science and engineering that address the needs of the DOE and other customers. Relevant to CAES, INL's energy security research and development is of paramount importance. These efforts are focused on four key challenges associated with energy security-production, distribution, protection, and environmental stewardship. CAES and EPI are seen as an integral part of this energy security strategy as illustrated in Figure 6.

INL researchers are actively engaged with CAES in the areas of fossil fuel, geothermal, bio-energy and other renewable energy source production. INL efforts to modernize the nation's energy infrastructure will also be key to ensuring safe and secure energy generation, distribution, use and conservation.

\subsubsection{Legal}

The INL Office of General Counsel will provide CAES with legal support prior to separate incorporation. This legal support will be limited to BEA's legal involvement within CAES. 
As CAES develops, legal activities will include outside legal counsel, contractual agreements such as partnering agreements and leases, joint appointment frameworks, employment agreements, and intellectual property protection including patents, copyrights, licenses and export controls. These services will help CAES achieve its business objectives while minimizing legal risks and expenses.

\subsubsection{Finance}

The INL Financial Operations organization will initially be used by CAES (prior to separate incorporation) to establish, maintain, and control the CAES financial accounts and reports, payrolls, travel accounts, and benefits. These services will be critical for ensuring adequate control of all funds consistent with INL financial controls including accurate recording of sales, revenues, and expenditures.

\subsection{University Consortia}

The Center will establish key academic networks to integrate its efforts. Several key university networks have already been formed.

\subsubsection{Idaho University Consortium}

The Idaho Universities Consortium (IUC) consists of three Idaho research universitiesIdaho State University, University of Idaho, and Boise State University. The principal research officers, i.e., the Vice Presidents (VP) for Research at the University of Idaho and Boise State University, and the Vice President for Academic Affairs at the Idaho State University, serve as the representatives of these institutions. These individuals provide technical and programmatic oversight via the CAES Steering Committee.

IUC will provide vital resources and expertise to CAES researchers and students. These resources include: engineering, biology, chemistry, mathematics, health physics, geology, hydrology, public policy, and information science.
The IUC and its affiliate Universities have established Institutes, Centers, and research departments that will collaborate with CAES. MOUs are being established between INL/BEA and the three IUC universities that define the establishment of CAES as a joint institute.

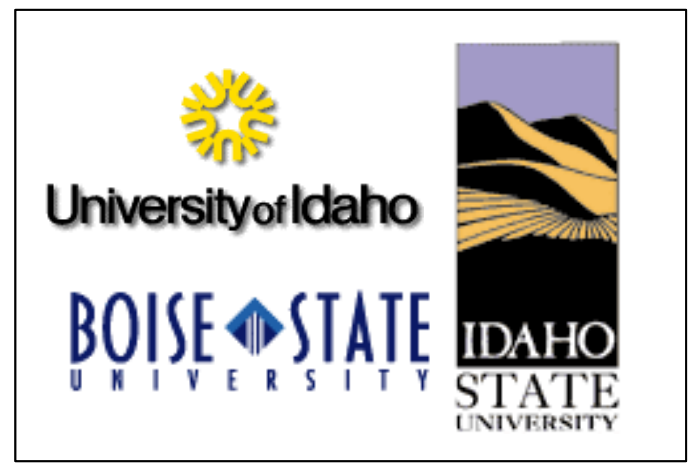

\section{Institute of Nuclear Science and Engineering}

A key component of the IUC is the Institute of Nuclear Science and Engineering (INSE). INSE is a collaborative Institute comprised of ISU, UI and BSU. It is an administrative entity of ISU, approved formally by the Idaho State Board of Education, and supported by BSU and the UI. INSE is to be governed by the IUC representatives, namely the VP Academic Affairs at ISU, and the VPs for Research at BSU and the UI.

Through INSE, the three universities jointly focus on nuclear science and engineering education and research at the combined University Place campus in Idaho Falls, and at the main campuses of the IUC institutions. INSE will be a strong implementation mechanism for IUC and CAES by bringing Idaho university resources in nuclear energy, nuclear engineering, nuclear science, and public policy related to energy to the INL community, through CAES.

\section{Idaho Accelerator Center}

The Idaho Accelerator Center (IAC) is a unique research facility operated by ISU (see Figure 10). The Center has the following key capabilities: 10 Operating Accelerators; Instrumentation and Mechanical Fabrication Support; Radiography, Tomography, and 
Nuclear Techniques for Nondestructive Assay; Instrument and Radiation Detectors; Radiation effects in biological and electronic systems; and experienced nuclear physics and nuclear science support.

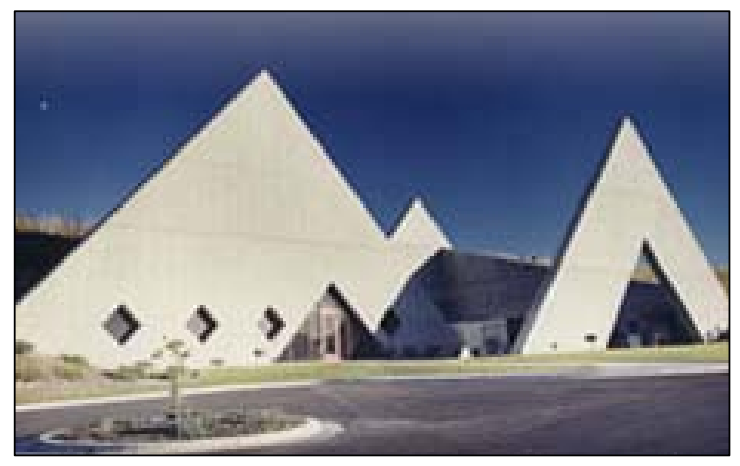

Figure 10. The Idaho Accelerator Center.

The Center researchers will cooperate with IAC consistent with a MOU that governs a wide range of joint activities. A significant advantage of this agreement is easy access to this equipment by universities, government agencies, and the private sector.

\subsubsection{National University Consortium}

The National University Consortium (NUC) consists of academic representation of five national universities. These five NUC universities include: Massachusetts Institute of Technology (MIT), North Carolina State University, the Ohio State University, Oregon State University, and the University of New Mexico.

These NUC organizations are of critical importance to the future of the nation's nuclear industry and will assist CAES in accessing academic expertise via the establishment of university-based Academic Centers of Excellence (ACE). ACE will channel academic expertise to CAES programs, collocated Centers and affiliate researchers. MIT will provide ACE expertise for Advanced Energy Systems; Oregon State University will provide ACE expertise for Thermal Fluids and Reactor Safety; North Carolina State University will provide ACE expertise for Modeling and Simulation; the Ohio State University will provide ACE expertise for Instrumentation and Control (I\&C) and Safety of Advanced Energy Systems; and the University of New Mexico will provide ACE expertise in the area of Space Nuclear Power.

As CAES expands beyond its initial membership (INL and the three Idaho universities) the NUC universities are expected to become the charter members of the wider CAES Idaho Affiliated University Network (IAUN), which will more formally engage the NUC in CAES. This development is expected to occur in FY-06.

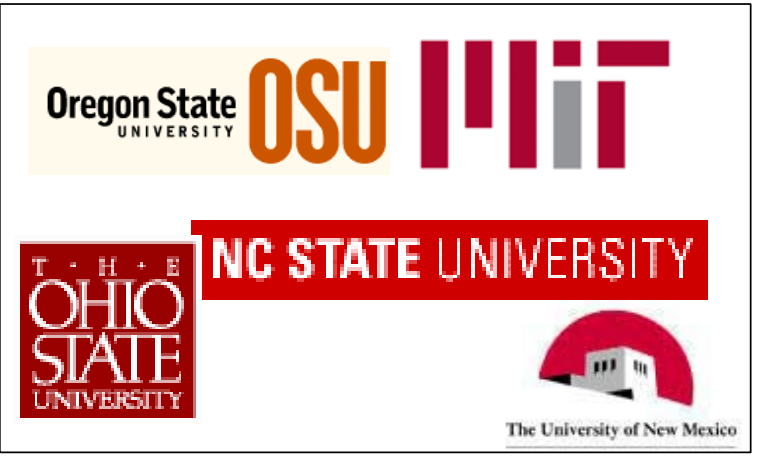




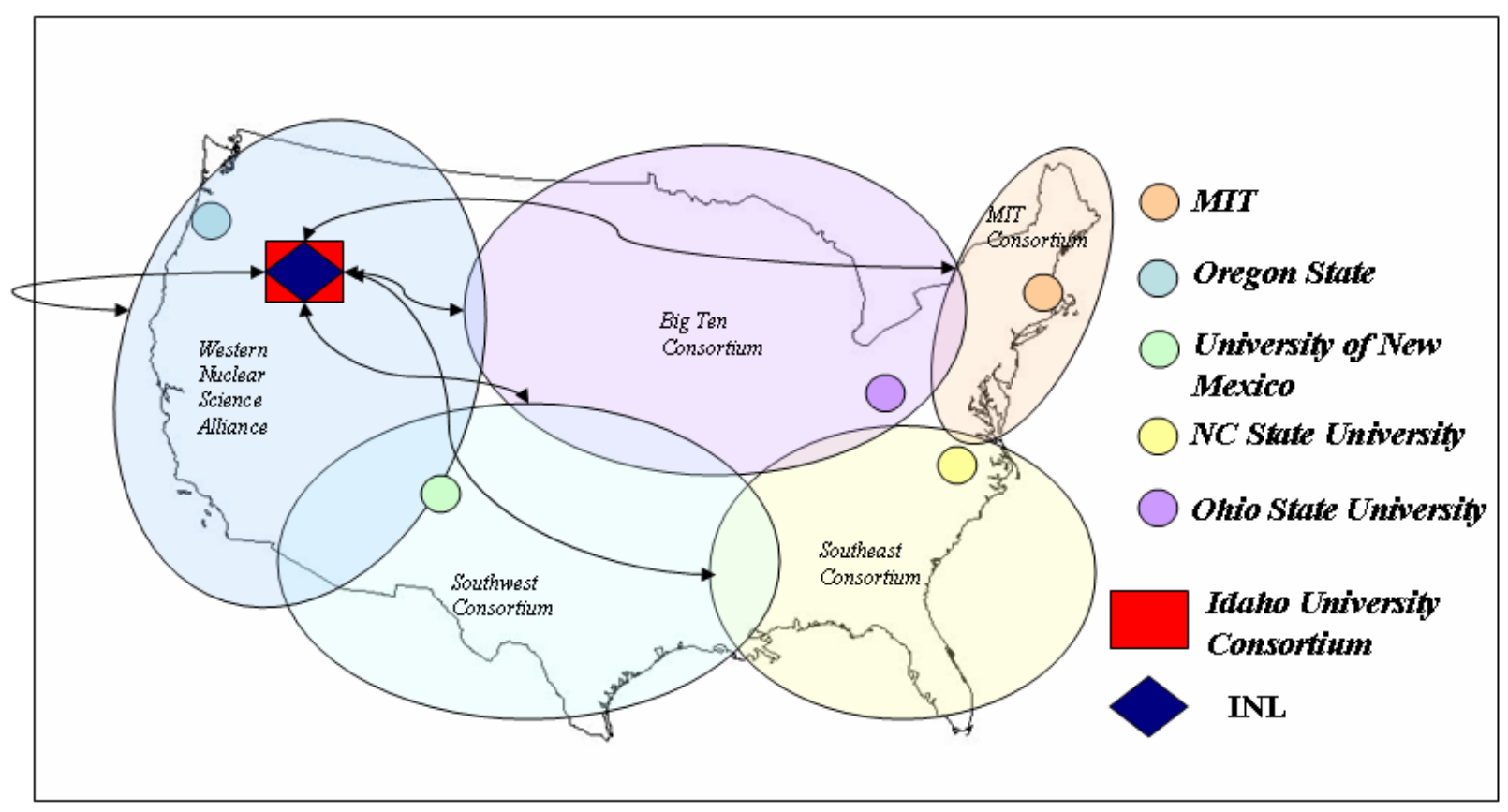

Figure 11. Illustration of the Idaho Affiliated University Network.

\subsubsection{Idaho Affiliated University Network}

The NUC and the IUC will work in partnership with CAES to form the Idaho Affiliated University Network (IAUN) (see Figure 11). A goal of this network is to assist the Idaho universities to reach first-tier academic and research status. The NUC ACEs will form a natural academic conduit fostering collaborative research among the IUC, NUC and INL.

\subsection{CAES Affiliate Network}

The Center will establish additional affiliations to further access the necessary worldclass talent required to achieve the vision.

Several key affiliates of this network are in place and actively engaged with CAES. Additional affiliate institutions will be incorporated into the activities of CAES as the Center progresses. Examples of such affiliated organizations are the Dalton Nuclear Institute (DNI), the World Nuclear University, Generation IV International Forum, the Western Strategic Energy Research Center the National Energy Foundation, the Joint Global Change Research
Institute, and the Center for Process Analytical Chemistry.

\subsubsection{Dalton Nuclear Institute}

The University of Manchester has established the Dalton Nuclear Institute (DNI). The DNI operates on an interdisciplinary basis, thus the Institute's interests extend beyond the more traditional areas of engineering, physics and chemistry into medical applications, nuclear decommissioning and fusion.

The Institute provides the focal point for the University's nuclear research activities and interacts with external bodies nationally and internationally with the intent of establishing the University of Manchester as the United Kingdom's leading university in nuclear research and education and one of the principal international players in this field. Along these lines, the Dalton Nuclear Institute coordinates the Nuclear Technology Education Consortium (NTEC) which consists of 12 universities and research institutes who together represent $90 \%$ of nuclear postgraduate teaching expertise in the UK. 


\subsubsection{World Nuclear University}

The mission of the World Nuclear University (WNU) is to strengthen the international community of people and institutions so as to guide and further develop the safe and increasing use of nuclear power as the one proven technology able to produce clean energy on a global scale and the many valuable applications of nuclear science and technology that contribute to sustainable agriculture, medicine, nutrition, industrial development, management of fresh water resources and environmental protection. This worldwide organization coordinates, supports and draws on the strengths of established institutions of nuclear learning.

\section{World Nuclear University - Summer Institute 2005}

The WNU Summer Institute 2005, developed in cooperation with the International Atomic Energy Agency, the Nuclear Energy Agency (NEA), the World Association of Nuclear Operators (WANO), and the World Nuclear Association (WNA), was conducted in Idaho Falls during July/August, 2005 (see Figure 12).

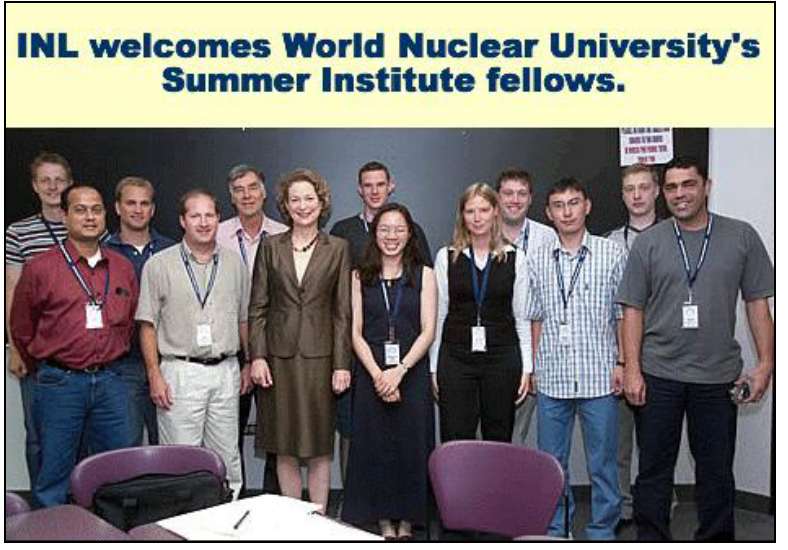

Figure 12. World Nuclear University's 2005 Summer Institute at the INL.

The INL and IUC, in support of the worldwide renaissance in nuclear energy, hosted $77 \mathrm{WNU}$ fellows from 33 nations. These individuals participated in education, research, and dialogue with the world leaders in nuclear energy, energy security, and strategic planning. It is being proposed to the DOE that additional WNU
Summer Institutes be hosted by CAES, the IUC, and the INL, and that CAES/IUC/INL become more involved with evolving WNU activities.

\subsubsection{Generation IV International Forum}

INL is assembling an international group of preeminent research directors and policy experts from industry, academia, national laboratories and government to develop an integrated global nuclear energy agenda.

The Center will work with this group to contribute to the formulation of a national agenda in 2006. Subsequently, an international agenda will be developed under the auspices of the Generation IV International Forum (GIF).

\subsubsection{Western Strategic Energy Research Center}

A Western Strategic Energy Research Center (WSERC) is being established by the INL, with initial focus on coal utilization projects in Wyoming. A partnership with the University of Wyoming is currently being established for research collaboration that will support future energy solutions for low rank coal and oil shale. It is anticipated that WSERC will be expanded to include other universities, various industrial companies (energy, coal mining), and government agencies. International participation is also anticipated (i.e., China).

A primary focus of this Partnership is to develop technologies to efficiently use western low-rank coals that are not well suited for the current generation of coal gasification technologies. During 2006 WSERC will further develop its partnerships and research agenda. CAES will provide access to common economic and process modeling capability, trained economists and policy analysts, and maintain a common repository of data to allow effective collaboration among both local and distant users.

\subsubsection{Other CAES Affiliates}

Additional CAES Affiliate organizations will be incorporated into the Program as its business elements mature. 


\section{PROGRAM ELEMENTS}

The Center has been organized to facilitate the execution of world-class Research, Education, Training and Policy formulation. In support of these four technical work elements are three mission-support enabling elements (Administration, Infrastructure, and Collaborative Relations). These seven work elements, as represented in the Work Breakdown Structure (WBS) shown in Figure 13, represent the unique work activities to be performed and products to be delivered by CAES. Additional information regarding these work elements is presented in the following sections.

\subsection{Work Breakdown Structure}

\subsubsection{Administration}

The Administration Work Element involves the following activities that are necessary to enable implementation of the CAES technical agendas (i.e., research, education, training, policy).

\section{Governance}

The CAES Governance work element will include the activities necessary to establish and manage the governing bodies of CAES. This includes establishment of the Executive Advisory Committee (Board of Governors), the Technical Advisory Committee and the CAES Steering Committee.

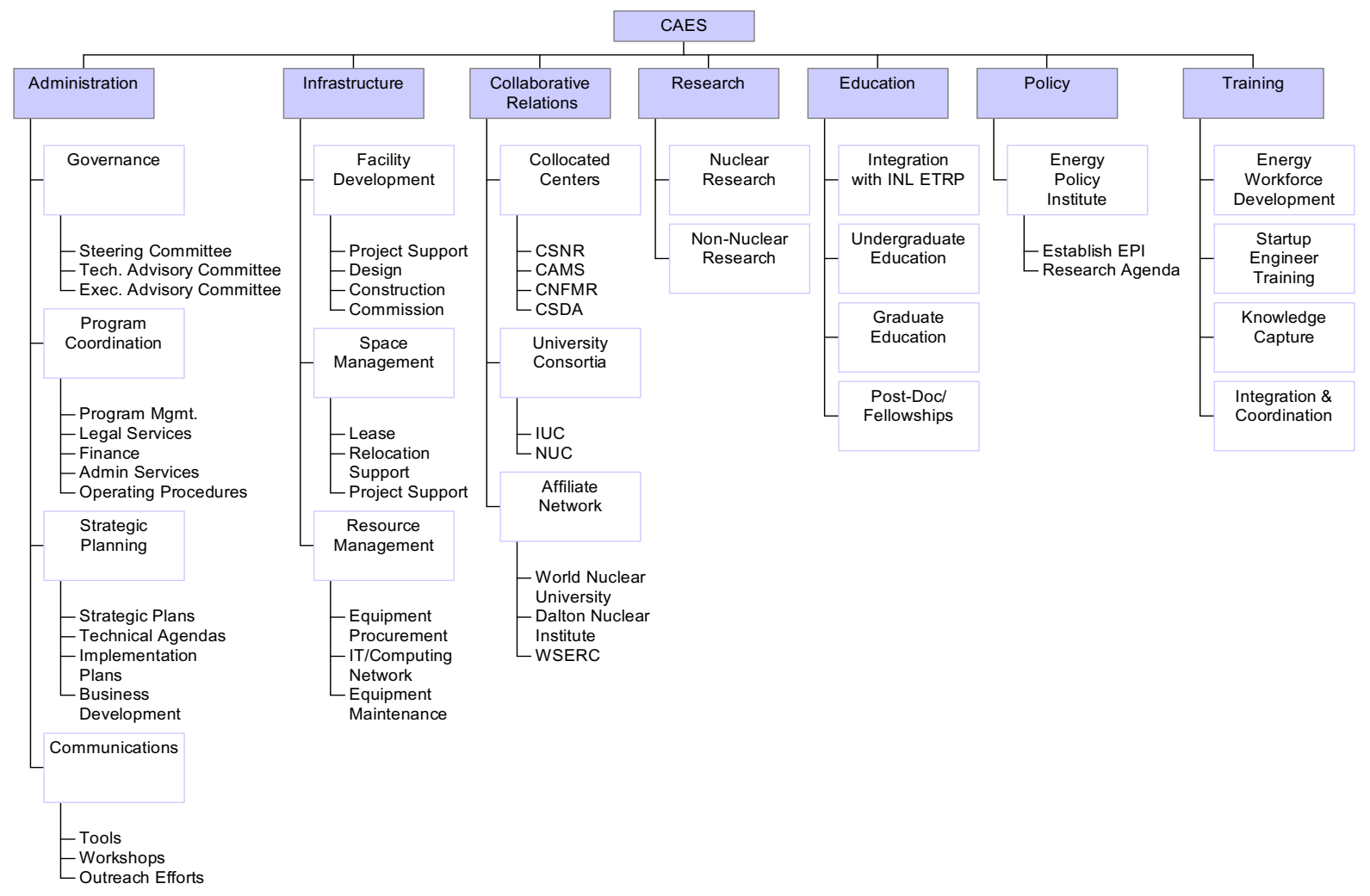

Figure 13. CAES Work Breakdown Structure. 


\section{Program Coordination}

The CAES Program Coordination work elements will perform the activities necessary to support planning, and execution of the CAES Program. These activities include program and project management, establishment and management of CAES baselines, cost control tracking and reporting, change controls, and administrative support.

Also included within the Program Coordination element is the management of CAES legal, financial and contractual mechanisms that are necessary to establish partnership arrangements (MOUs, MOAs, etc.), intellectual property management and subcontracting.

As CAES moves to create a positive technical environment that supports the development of collaborative research and development partnerships, it will be important to establish researcher-friendly operating procedures and policies that enable, rather than hinder, the CAES research teams. This work element will work with CAES researchers to establish streamlined security procedures to accommodate non-U.S. citizens; an agile administrative system to create cooperative legal agreements and mechanisms to accomplish Environmental, Safety, Health and Quality (ESH\&Q), records management and publication requirements.

\section{Strategic Planning}

As CAES progresses it is imperative that it develop and maintain current Strategic Plans, distinctive signatures, technical and policy agendas, and implementation plans so that CAES can achieve critical mass in terms of intellectual and business activities. The Strategic Planning work element will manage these elements of the CAES Program. Also included within this element will be the Proposal Development mechanisms whereby CAES and its partners will develop technical proposals consistent with its strategic plans and technical and policy agendas.

\section{Communications}

The Communications work element will consolidate CAES communication efforts so as to develop a clear and consistent message.
Communication efforts include organized events (public ceremonies, news/media events), technical exchanges (workshops, seminars, conferences), informational materials (newsletters, news webpages, presentations, graphics), general communications (public, employees, students) and community outreach efforts. A CAES Annual Report will also be produced.

\subsubsection{Infrastructure}

The Infrastructure work element will manage the CAES infrastructure-related activities. This element includes Facility Development collaboration efforts related to the design and development of the CAES building; Space Management efforts such as INL/CAES lease arrangements for the building and temporary space management; Resource Management activities such as equipment acquisition, equipment maintenance, advanced computing and simulation capabilities management, and the establishment and management of a modern electronic communications network.

\subsubsection{Collaborative Relations}

The Collaborative Relations work element will capture those unique activities that are necessary to establish and maintain the CAES external partnerships. Four types of partnerships are currently envisioned depending on the organizations involved. These include the collocated Centers, the university consortia, the affiliate network, and other partners.

\subsubsection{Research}

The Center will conduct and participate in research involving a broad range of energy-related topics. Nuclear and non-nuclear energy research will be performed for a variety of sponsors. This work will involve U.S. federal sponsors, private sector sponsors, international sponsors, university sponsors, etc. This work element will provide a management structure suitable for organizing and coordinating this diverse range of research.

The Center research clusters will serve to concentrate its resources. The results of research will be presented in peer-reviewed publications, conferences, and reports. A summary of activities 
will be presented at the annual meeting and in the annual report.

\subsubsection{Education}

The Center and its affiliate organizations will be involved in a range of educational efforts and academic programs. The INL ETRP will be an important partner for successfully implementing this work. Within the CAES WBS, this work element, under the direction of the CAES Associate Director for Education, will coordinate CAES-related educational activities that will be implemented collaboratively with its affiliate institutions. The Education work element includes the following sub-elements.

\section{INL Academic Center of Excellence, Inc.}

The INL Academic Center for Excellence, Inc. (ACE, Inc.) is a 501(c) (3) corporation that administers Pre-College and University fellowships at INL, as well as the INL Scholastic Tournament. ACE, Inc. was established in 1999 to administer programs which encourage scientific and academic excellence at INL, assist promising students to obtain post-secondary education in scientific fields, assist students and faculty with short-term research projects relating to their educational goals, and encourage secondary school students to pursue careers in science and mathematics by promoting academic competitions in the area, at the secondary school level.

\section{Fellowship Program}

Collaboration between academia (undergraduate, graduate, and faculty) and CAES scientists and engineers increase the exchange of ideas, information and technology. The INL/CAES fellowship program will focus on bringing university students and faculty to the INL/CAES. Particular emphasis will be placed on increasing the number of postdoctoral, female, and minority investigators at the laboratory.

\section{Postgraduate Program}

The Postgraduate program will provide college graduates who have completed all institutional requirements for a Bachelors, Masters, or Doctoral degree from an accredited college or university with research experience and opportunities to explore their major discipline in a real world environment through involvement with INL/CAES mission-related projects. In collaboration with Washington State University (WSU), an INL ETRP staff member will administer this postgraduate internship program. The participants become WSU employees, thereby incorporating their appointments and payments into WSU's customary policies and procedures. Selection of participants is competitive and is based on applicant qualifications, interests and compatibility with the needs and resources of the INL/CAES, career goals, references, and the projected benefit of the experience to the individual and the INL/CAES. Assignment to the INL/CAES may be up to three years.

\section{International Research Associate Program}

The International Research Associate Program provides undergraduate students, graduate students and faculty, who are not citizens or permanent residents of the United States, with the opportunity to work on research projects at the INL. In collaboration with WSU an INL ETRP staff member administers the IRA program.

\section{Pre-College Programs}

The Center will coordinate with and rely upon the INL ETRP for a variety of pre-college programs. Currently, the INL supports the INL Scholastic Tournament, the DOE National Science Bowl, a 10-week DOE Pre-Service Teacher Program, an eight-week Teaming Teachers with INL summer program, and an eight-week Student Action Team summer program.

\subsubsection{Policy}

The Center will provide international, national, and regional leadership on energy-related policy issues. This work element will coordinate and manage the CAES Policy-related efforts.

The CAES EPI is the key component of this work element. CAES EPI will develop, during FY-06, a CAES Policy Research Agenda that will define specific areas of focus for this work element. It is envisioned that additional Policy sub-elements will be added. For example, there is growing realization with regard to Energy-Water 
interdependences. As such this presents an opportunity whereby policy formulation will be critical.

\subsubsection{Training}

The Center will help resolve a pressing dilemma in the energy industry; the need for new skilled crafts and maintenance workers and trained technicians that are necessary to replace the current aging workforce. This work element will coordinate CAES training elements including the introduction of a new generation of pre-college and non-college bound workers to the energy sector. This work element will also develop the vehicles whereby this new workforce and those already in the field can adequately train to gain or maintain proficiency in their field.

The CAES Training and Workforce Initiatives are initially focused on five primary components:

- Engage CAES in the national energy sector training dialogue
- Using a CAES-developed technical training roadmap, define and deliver critical technical training for engineers, staff and trainers

- Improve outreach efforts for pre- and noncollege bound workers to promote a more robust and reliable energy sector "people pipeline"

- Define and establish a supportive educational, employer, and professional association training infrastructure for non-college bound energy sector staff

- Define, develop and promote methods for energy sector knowledge capture.

During FY-06 the CAES Training Agenda will be further refined and developed in concert with CAES affiliates to define the goals, projects and metrics for this work element.

\section{BUSINESS MODEL}

The Center researchers and technical staff will engage in core research, education, training and policy activities. Collaborative projects and joint proposals with its collocated, independent centers and university and affiliate partners will also be pursued. In the course of normal operations CAES will generate revenue from research, policy studies and training activities. CAES will incur personnel and other operating costs in support of its employees and building. CAES and its collaborating and affiliated entities will operate as a "loose confederation". CAES is investigating the NSSTC structure, discussed in Section 4.1.9, as a possible model for operation.

For the purpose of this section, CAES is defined as the Core CAES organization, EPI, and some fraction of students and faculty engaged in CAES projects and housed in the CAES building. The Core CAES organization includes the CAES Director, three Associate Directors, one Manager, five research Fellows, a Deputy Director of Operations and two administrative staff.
The revenue, cost and staffing projections are consistent with the DOE Field Work Proposal dated March 9, 2005 and represent the minimum amounts necessary to ensure the long-term success of CAES. The cost and staff projections are discussed below.

\subsection{Projected CAES Revenue}

Core CAES revenue consists of research funding obtained by the five CAES Fellows, EPI, and, through 2011, financial support from both the DOE and the INL. Beginning in FY-08 sublease payments from CAES affiliates are also included. Core CAES costs include personnel costs associated with thirteen FTEs and other standard operating costs.

It is the intent of CAES to be an independent self-sustaining entity no later than the beginning of FY-12. To meet this objective it is critical that CAES receive the projected funding support from the Department of Energy and the INL during 
Phases 1 and 2 of its development. Over the fiveyear period FY-07-11 a total of $\$ 29.5 \mathrm{M}$ in DOE direct funding support is required to ensure the long-term viability and eventual world-class status of CAES. During the same period $\$ 7.5 \mathrm{M}$ in INL indirect support is required. CAES Fellows are expected to generate approximately $\$ 9.5 \mathrm{M}$ in total revenues over the same period. DOE and INL financial support will end beginning in FY-12. At that time CAES Fellow, EPI and sublease revenues are expected to be sufficient to cover ongoing expenses. Figure 14 shows the breakdown of CAES revenue for the period FY07-16.

\subsection{Projected CAES Costs}

Figure 15 shows the breakdown of CAES costs for the period FY 07-16. Personnel costs account for over $90 \%$ of total Core CAES costs. Two significant pieces of research equipment will be purchased in FY-08 and FY-09 contributing to the spike in costs indicated in those years. FTE's are assumed to be $50 \%$ INL and 50\% non-INL employees and are fully burdened using a labor factor of 2.769 and 2.0 respectively.

Based on the revenue and cost projections discussed above, CAES is expected to realize a positive net cash flow throughout the period FY07-16. Any positive cash flow will be reinvested into CAES in the form of staffing, and business development efforts, so as to enable CAES to achieve its business goals.

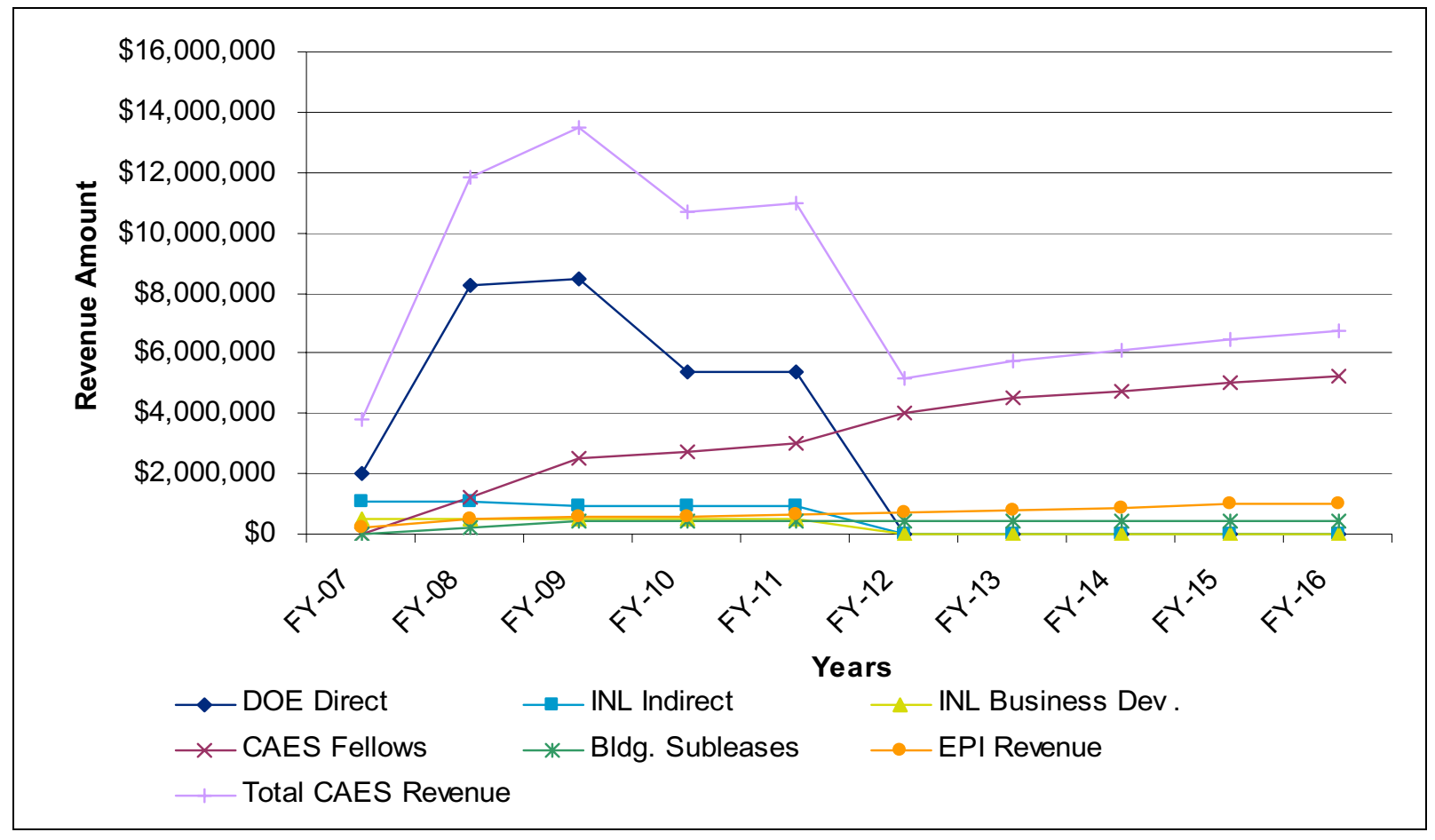

Figure 14. Breakdown of CAES Revenue. 


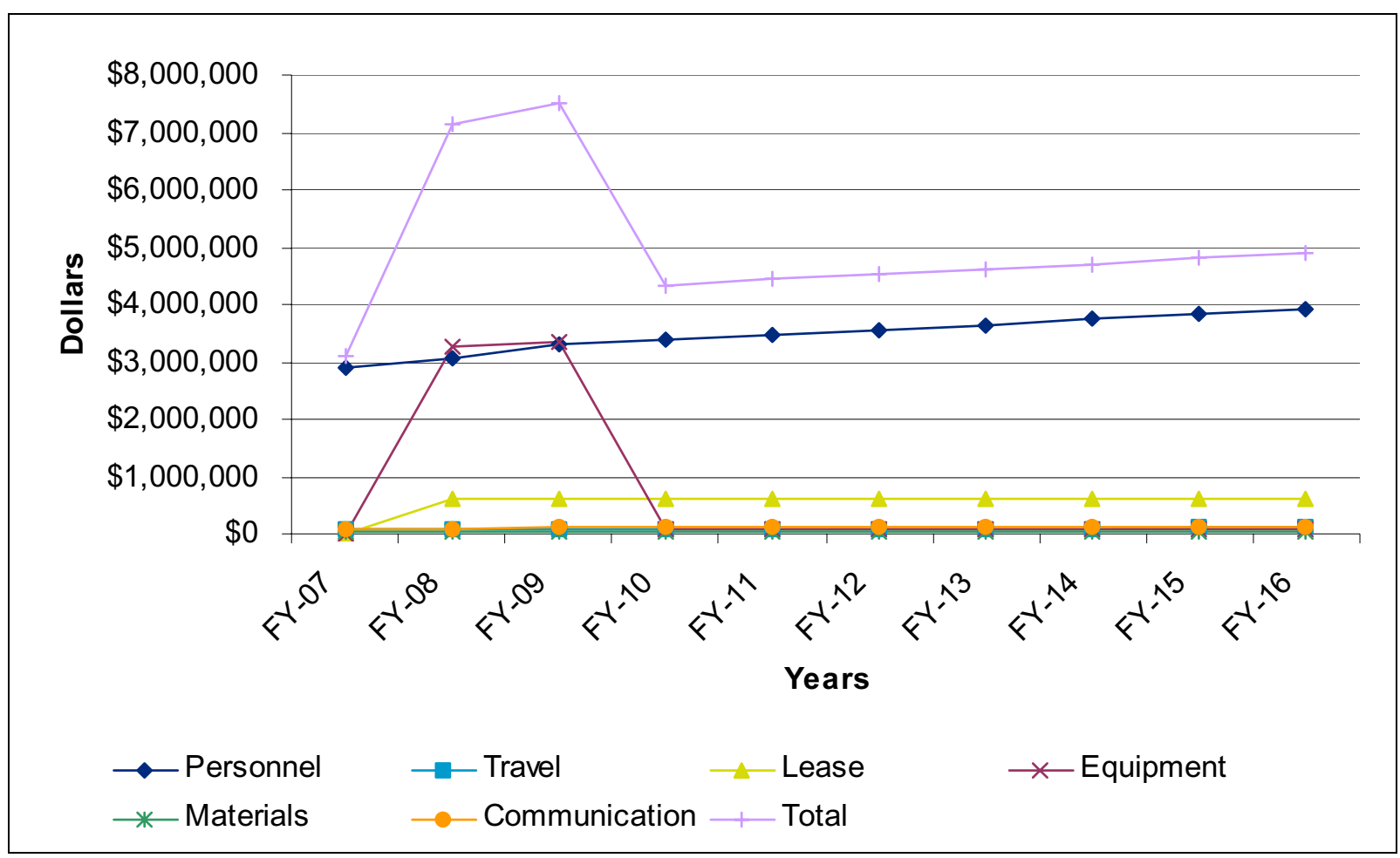

Figure 15. Breakdown of CAES Costs.

\subsection{Staffing Plan}

The projected CAES staffing levels have been derived from scoping information developed in support of the new CAES facility. Based on this scoping data, it is estimated that CAES will be fully-staffed at thirteen Full Time Equivalents (FTEs) as follows: CAES Director, Training \& Workforce Initiatives Manager, Associate Director of Energy Policy, Associate Director of Education, Associate Director of Research, five CAES
Research Fellows, a Deputy Director for Operations and two administrative employees. Additionally, 10-12 CAES researchers or graduate students are anticipated to be housed at the CAES facility by 2010 .

As previously discussed, additional researchers and technical staff from EPI, the collocated Centers, and affiliated organizations will have FTEs located in the CAES facility. The projected distribution of these related staff is anticipated to be approximately 105 by 2010 .

\section{RISK ASSESSMENT}

Several significant risks have been identified that could adversely impact the execution of this Program Plan and thereby impact the success of the CAES Program. This section discusses these risks and presents proposed mitigation actions, which will minimize or neutralize these risks.

\subsection{Programmatic}

Stiff competition, flat federal research and development (R\&D) budgets and changing federal policy and priorities result in CAES failing to generate funding sufficient to cover its operating costs. 
Mitigation Actions: Given the projected budget profile and highly competitive nature of the federal R\&D market a well-thought out and detailed business development strategy is key to CAES success. It is essential that a clear and concise programmatic agenda be developed and implemented by CAES and its partners prior to the development of the business development strategy. Development of a comprehensive business plan including a fully developed marketing plan is essential. This activity needs to be initiated in FY-06 and maintained in subsequent years. In order to broaden its potential market beyond the federal R\&D sector, CAES must also exploit to the highest degree possible its ties to private industry through the BEA team, and universities. To broaden its accessible market CAES must also aggressively pursue nonprofit status so that wider ranges of potential funding sources are available.

\subsection{Infrastructure}

Federal and State review and approval delays of the CAES facility could negatively impact the design and construction schedule resulting in a completion date delay beyond the target 2008 date. Specifically, DOE facility development requirements could delay the building construction process.

Mitigation Actions: BEA is working with DOE-ID to resolve the review and approval requirements for the CAES facility. The facility is expected to be a university building on university land. BEA is supporting IUC in defining the review and approval requirements for the State of Idaho. Appropriate resolution of this issue and presentation to the State Board of Education by December 2005 will minimize schedule delays.

\subsection{Legal}

\subsubsection{Nonprofit Status}

Although CAES is expected to transition to a separately incorporated nonprofit company, CAES may not be able to solicit and receive certain funding prior to obtaining tax-exempt, charitable status under section 501(c)(3) of the Internal Revenue Code.
Mitigation Actions: Efforts to compile the necessary financial data to complete Part IX of IRS Form 1023, "Application for Recognition of Exemption under Section 501(c)(3)" will aid CAES's efforts to obtain tax-exempt status as quickly as possible. It is possible to apply for such status if CAES is in existence less than four (4) years, but CAES must complete financial statements for each year in existence and provide projections of likely revenues and expenses based on a reasonable and good faith estimate of future finances for a total of three (3) years of financial information.

\subsubsection{Risk Management}

Initially BEA's Office of General Counsel and legal staff of affiliated entities will provide legal support for CAES with respect to drafting and negotiating various agreements that will be needed for the formation and operation of CAES as a nonprofit entity, however long term risk management and legal support will need to be provided for CAES.

Mitigation Actions: It is envisioned that in due course after CAES has formally been established and is operating as a nonprofit company, CAES will obtain independent legal counsel to advise the governing board and provide legal support with respect to risk management and other legal issues.

\subsubsection{Intellectual Property}

Because collaborative research efforts will involve the interactive participation of employees of BEA, employees of the respective members of the IUC, as well as employees and individuals associated with other entities, it is expected that various CAES affiliated entities will have an interest in the ownership of intellectual property resulting from the research efforts. Furthermore, entities providing funding for research efforts will likely have expectations, if not requirements, with respect to the ownership and/or the licensing of intellectual property resulting from such funded research efforts.

Mitigation Actions: Agreements addressing intellectual property ownership and licensing arrangements will need to be negotiated and 
executed prior to all research efforts that are undertaken by CAES. Furthermore, all such agreements in which BEA is a party will need to have terms and conditions which are consistent with BEA's Management and Operating Contract.

\subsubsection{Conflict of Interest}

Because it is anticipated that research efforts will be conducted on behalf of a variety of funding sponsors, there will be a need to identify potential conflict of interests with respect to conducting research efforts on same or similar technical subject matter on behalf of different funding sponsors that may be business competitors.

Mitigation Actions: A sponsor/technical subject matter conflict of interest check will need to be conducted by CAES and the respective CAES associated entities prior to executing agreements for research efforts and other activities.

\subsubsection{Confidentiality}

It is likely that sponsors funding research efforts at CAES will need to disclose confidential/ business sensitive information to the respective CAES associated entities prior to and while research efforts are being conducted.

Mitigation Actions: A procedure for negotiating, executing, and managing nondisclosure agreements and confidentiality obligations in research agreements, including identifying potential conflict of interest concerns, will need to be maintained by CAES and the affiliated entities.

\subsection{Financial}

Several financial risks have been identified in association with CAES.

\subsubsection{DOE Funding Limitation}

DOE funding to support CAES during its development period (FY-07-14) is insufficient to adequately launch CAES.

Mitigation Actions: CAES, in conjunction with senior management at INL and its university partners, must develop and execute a wellorchestrated strategy to establish DOE funding support for CAES. Frequent contact with senior DOE officials and the Idaho and other congressional delegations is a key component of this strategy. A consistent message that CAES requires a significant operating budget to ensure success is the unifying theme underlying the communication strategy.

\subsubsection{CAES Competes with INL}

The Center competes directly with INL for R\&D funding thereby reducing both organizations funding base.

Mitigation Actions: In developing its research agenda, CAES and its partners must clearly delineate $R \& D$ scope and $R \& D$ markets to be pursued by CAES. To the fullest extent possible INL and CAES scope should avoid overlap to reduce the potential for competition. In areas where overlap between INL and CAES will inevitably occur a protocol for customer contact and bid/proposal activities is advised. The sales credit system set up at the INL should, to the fullest extent possible, facilitate cooperative research rather than hinder it.

\subsubsection{Failure to Establish Charging Practices}

CAES fails to successfully collaborate with the INL and its various partners in the development and implementation of innovative charging practices and other business-related policies that facilitate the sharing of resources and joint $R \& D$.

Mitigation Actions: INL, CAES, and CAES partners commit sufficient resources to developing the agreements, policies and procedures necessary to ensure CAES success. Each entity must push beyond its comfort zone and break down barriers that may stand in the way of CAES success. Where applicable CAES must seek lessons learned from related efforts and avoid similar pitfalls.

\subsubsection{Failure to Establish Collaborations}

The Center and its partners fail to develop a detailed business plan and critical path in a timely manner. 
Mitigation Action: During FY-06 CAES partners must be engaged in the development of a detailed business plan complete with a welldeveloped marketing plan.

\subsubsection{Staffing}

The Center and its partners fail to attract and retain the technical expertise necessary to develop and implement world-class research, policy, training and education.

Mitigation Action: INL, CAES, and CAES partners must commit during 2006 to make available key personnel and resources sufficient to establish a critical staffing base. Additionally, CAES must work with all of its affiliate organizations to establish competitive salaries, benefits packages and resource commitments sufficient to attract the necessary talent that will be needed to achieve the CAES vision. From this base CAES and its partners must develop longrange staffing projections.

\subsubsection{CAES Competes with Established Energy Organizations}

The Center competes directly with established industry and professional organizations funded by their members in the energy sector and specifically the nuclear sector with respect to mission responsibilities.

Mitigation Action: CAES management will develop relationships with leaders from these organizations. CAES will present itself as complementary to meeting overall energy and nuclear sector mission objectives and show it is able to facilitate implementation of activities and programs to meet these goals with a level and diversity of technical expertise unavailable to these organizations. Close ties to DOE, the NRC, Energy Information Administration and Federal Energy Regulatory Commission will be developed to promote an understanding of the issues from, not just a commercial perspective, but a regulatory and policy perspective as well. Cooperative ventures should be identified between EPRI and CAES

\section{ENVIRONMENTAL, SAFETY \& HEALTH CONSIDERATIONS}

The Center activities will be performed in a safe, secure, cost-effective, and compliant manner to ensure worker safety as well as protection of facilities, the environment and the public through the identification, analysis, and mitigation of safety and health hazards.

All CAES work performed by INL staff or affiliated with INL fund sources will be conducted consistent with applicable INL Environmental, Safety, and Health (ES\&H) requirements and Integrated Safety Management System (ISMS) procedures (see Figure 16). These requirements include, but are not limited to, environmental protection, occupational health, emergency preparedness, and safety.

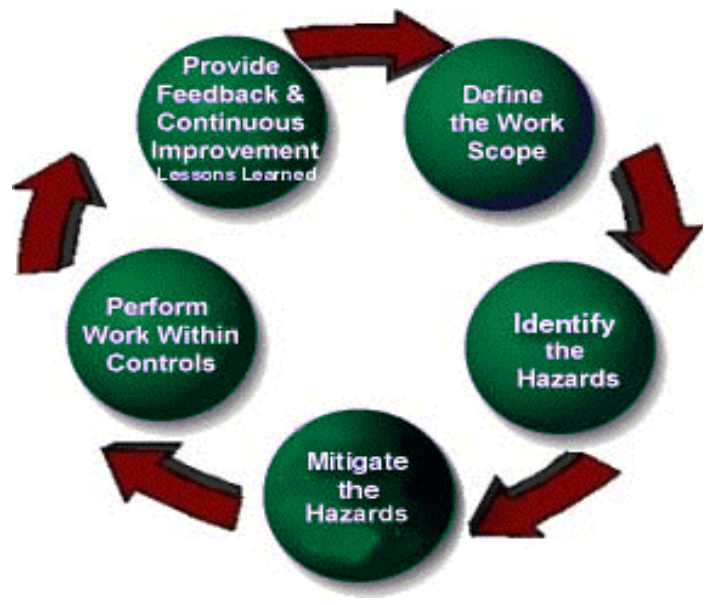

Figure 16. ISMS Core Functions. 


\section{QUALITY ASSURANCE CONSIDERATIONS}

The Center is committed to producing the highest quality products and services to meet customer expectations. To achieve this commitment, CAES will implement the INL quality assurance (QA) program that promotes the achievement of quality through (a) planning and documentation of requirements for items, processes, and services; (b) controlling activities affecting the quality of those items, processes and services; (c) verifying the achievement of required quality; and (d) analyzing and correcting conditions adverse to quality in a continuing process of self-improvement.

\section{SAFEGUARDS \& SECURITY CONSIDERATIONS}

The Center activities will be performed in a safe and secure manner, which balances the programmatic goals and objectives along with national security and safeguards requirements. All CAES work performed by INL staff or affiliated with INL fund sources will be conducted consistent with the INL Integrated Safeguards and Security Management (ISSM) program. ISSM is intended to provide a formal, organized process for planning, performing, assessing and improving the secure conduct of work in accordance with risk-based protection strategies.

\section{RECORDS MANAGEMENT}

To ensure the management of critical information, CAES will comply with the INL requirements for Records Management. This system complies with identified regulations and standards for consistent care of information including the creation or receipt, maintenance and use, and disposition of records.

\section{PROJECT CONTROLS}

The Center activities will be managed consistent INL Project Management requirements. These requirements include establishment of project cost and schedule controls for baseline management including work authorization and expenditure controls, performance monitoring and reporting, trend identification and baseline change controls. 


\section{REFERENCES}

(2005). Energy Policy Act of 2005. Public Law No: 109-58, August 8, 2005.

BEST (2004). The Talent Imperative: Meeting America's Challenge in Science and Engineering, ASAP. Building Engineering \& Science Talent, 2004.

Corradini, M. L., J. J. Duderstadt and W. R. Martin (2003). The Use of Undergraduate Minors to Meet National Needs in Nuclear Fission Power Engineering. ASEE Conference, 2003.

Gibbons, J. H. (1997). Report to the President on Federal Energy Research and Development for the Challenges of the Twenty-First Century. President's Committee of Advisors on Science and Technology, Executive Office of the President of the United States of America, November, 1997.

Magwood, W. D. (2002). University, Industry, and Government: Partners for the Future of Nuclear Engineering and Technology. U.S. Department of Energy, Office of Nuclear Energy, Science \& Technology, Presentation October 28, 2002, http://www.ne.doe.gov/.

NETF (2005). Moving Forward with Nuclear Power: Issues and Key Factors. Secretary of Energy Advisory Board, Nuclear Energy Task Force, Washington D.C., January 10, 2005.

O'Brien, C. and M. Louis (2005). Existing Energy Policy Institutes and Organizations in the U.S. - A Benchmark Study to Support the Start-up Project Plan for the Energy Policy Institute.

ORISE (2005). Nuclear Engineering Academic Programs Survey, 2004. Oak Ridge Institute for Science and Education, Oak Ridge, TN, Number 56, 2005.

Tester, J. W., E. M. Drake, M. W. Golay, M. J. Driscoll and W. A. Peters (2005). Sustainable Energy Choosing Among Options, The MIT Press, Cambridge, MA, ISBN 0-262-20153-4.

Was and Martin (2000). Manpower Supply and Demand in the Nuclear Industry. Nuclear Engineering Department Heads Organization (NEDHO), 2000.

Wogman, N. A., L. J. Bond, A. E. Waltar and R. E. Leber (2005). "The Nuclear Education and Staffing Challenge: Rebuilding Critical Skills in Nuclear Science and Technology". Journal of Radioanalytical and Nuclear Chemistry, 263 (1): 137-143. 